\title{
Declaración del Tribunal Constitucional sobre compatibilidad de la Constitución Española con la Constitución Europea
}

\author{
${ }^{*}$ DTG 1/2004, de 13 de diciembre de 2004
}

El Pleno del Tribunal Constitucional, compuesto por doña María Emilia Casas Baamonde, Presidenta, don Guillermo Jiménez Sánchez, don Vicente Conde Martín de Hijas, don Javier Delgado Barrio, doña Elisa Pérez Vera, don Roberto García-Calvo y Montiel, don Eugeni Gay Montalvo, don Jorge Rodríguez-Zapata Pérez, don Ramón Rodríguez Arribas, don Pascual Sala Sánchez, don Manuel Aragón Reyes y don Pablo Pérez Tremps, Magistrados, ha pronunciado

la siguiente

\section{EN NOMBRE DEL REY}

\section{E C L A R A C I Ó N}

Ante el requerimiento (asunto núm. 6603-2004) formulado por el Abogado del Estado, en nombre y representación del Gobierno de la Nación, acerca de la existencia o inexistencia de contradicción entre la Constitución española y los artículos I-6, II-111 y II-112 del Tratado por el que se establece una Constitución para Europa, firmado en Roma el 29 de octubre de 2004. Ha sido Ponente el Magistrado don Vicente Conde Martín de Hijas, quien expresa el parecer del Tribunal.

\section{Antecedentes}

1. Por escrito registrado en este Tribunal el 5 de noviembre de 2004 el Abogado del Estado, en la representación que legalmente ostenta y en virtud del Acuerdo adoptado por el Gobierno de la Nación en la reunión del Con-

\footnotetext{
* Por su interés reproducimos la Declaración del Tribunal Constitucional en relación con la existencia o inexistencia de contradicción entre la Constitución Española y determinados artículos de la Constitución para Europa incluida en el Tratado ya sometido a referéndum. La Declaración incluye tres votos reservados. En otros países de Europa la Doctrina está ampliando el campo de estudio entre las posibles contradicciones entre sus Constituciones y el Texto de la Europea.
} 
sejo de Ministros celebrada el 5 de noviembre de 2004, al amparo de lo dispuesto en el art. 95.2 de la Constitución y en el art. 78.1 LOTC, requiere a este Tribunal para que se pronuncie sobre la existencia o inexistencia de contradicción entre la Constitución española y el artículo I-6 del Tratado por el que se establece una Constitución para Europa, firmado en Roma el 29 de octubre de 2004, así como, a la vista de lo establecido en el art. 10.2 CE, sobre la existencia o inexistencia de contradicción entre la Constitución española y los artículos II-111 y II-112 del referido Tratado, que forman parte de la Carta de derechos fundamentales de la Unión Europea. Asimismo, y en función de la respuesta que reciban esas cuestiones, el Gobierno requiere al Tribunal para que se pronuncie acerca de la suficiencia del art. $93 \mathrm{CE}$ para dar cauce a la prestación del consentimiento del Estado al Tratado o, en su caso, acerca del procedimiento de reforma constitucional que hubiera de seguirse para adecuar el texto de la Constitución española al repetido Tratado internacional.

En virtud de lo anterior el Abogado del Estado interesa que, admitido su escrito, se tenga por formulado, en nombre del Gobierno, requerimiento a este Tribunal para que, con arreglo a los arts. 95.2 CE y 78.1 LOTC, tras la tramitación oportuna, emita una Declaración vinculante sobre los siguientes extremos:

1) La existencia o inexistencia de contradicción entre la Constitución Española y el artículo I-6 del Tratado por el que se establece una Constitución para Europa.

2) A la vista de lo establecido en el artículo 10.2 de la Constitución Española, la existencia o inexistencia de contradicción entre la Constitución Española y los artículos II-111 y II-112 del Tratado por el que se establece una Constitución para Europa, que forman parte de la Carta de derechos fundamentales de la Unión Europea.

3) La suficiencia o no del artículo 93 de la Constitución Española a los efectos de la prestación del consentimiento del Estado al Tratado por el que se establece una Constitución para Europa.

4) En su caso, el cauce de reforma constitucional que hubiera de seguirse para adecuar el texto de la Constitución Española al Tratado por el que se establece una Constitución para Europa.

2. El requerimiento del Abogado del Estado va acompañado de copia del Acuerdo del Consejo de Ministros de 5 de noviembre de 2004, en cuya virtud 
se requiere a este Tribunal Constitucional para que emita Declaración de conformidad con el art. 95.2 CE y el art. 78.1 LOTC.

Dicho Acuerdo gubernamental fundamenta el requerimiento planteado en una serie de consideraciones que se estructuran a partir de la exposición de los antecedentes que han llevado a la firma del Tratado por el que se establece una Constitución para Europa.

a) En esa línea se expone que la última reforma significativa del Tratado de la Unión y de los Tratados de las Comunidades Europeas, acordada en Niza en 2000, pronto se consideró insuficiente para hacer frente a las exigencias que conllevaría la ampliación de la Unión a Europa central y oriental y a las nuevas necesidades impuestas por una cambiante realidad en el plano económico, social e internacional, siendo también cada vez más evidente una creciente inquietud por el desapego de los ciudadanos hacia los asuntos europeos. En ese contexto la misma Conferencia Intergubernamental de Niza adoptó una Declaración relativa al futuro de la Unión, en la que hacía un llamamiento a un debate en profundidad, en el que deberían abordarse cuestiones como la forma de establecer y supervisar una delimitación más precisa de la distribución de competencias entre la Unión Europea y los Estados miembros, el estatuto de la Carta de los derechos fundamentales de la Unión Europea, la simplificación de los Tratados y la función de los Parlamentos nacionales en la arquitectura europea. Finalmente, la Conferencia acordó convocar una nueva Conferencia Intergubernamental en 2004.

Posteriormente la Declaración de Laeken de 15 de diciembre de 2001, realizada por los Jefes de Estado y de Gobierno de los Estados miembros, con el fin de "garantizar una preparación lo más amplia y transparente posible de la próxima Conferencia Intergubernamental", acordó "convocar una Convención que reúna a los principales participantes en el debate sobre el futuro de la Unión [para] examinar las cuestiones esenciales que plantea el futuro desarrollo de la Unión e investigar las distintas respuestas posibles".

El 18 de julio de 2003 el Presidente de la Convención entregó al Presidente del Consejo Europeo el Proyecto de Tratado por el que se establece una Constitución para Europa. El 18 de junio de 2004 los Jefes de Estado y de Gobierno de los Estados miembros alcanzaron un acuerdo sobre el texto del Tratado, que sería firmado en Roma el 29 de octubre pasado. La firma del Tratado por parte de España fue autorizada por Acuerdo del Consejo de Ministros de 22 de octubre de 2004. 
b) El Acuerdo del Gobierno se detiene, a continuación, en el examen de las principales características del Tratado por el que se establece una Constitución para Europa, destacando que supone una auténtica refundación jurídica de la Unión Europea, ya que, de acuerdo con su artículo IV-437, el nuevo Tratado deroga el Tratado de la Comunidad Europea y el Tratado de la Unión Europea, así como, en las condiciones previstas en un Protocolo anejo, los actos que los han completado o modificado. Del mismo modo quedan derogados los distintos Tratados de adhesión, con las salvedades establecidas en dos Protocolos.

Con la entrada en vigor del Tratado España no será ya miembro de la Comunidad y de la Unión Europea al amparo del Tratado de adhesión de 1985, sino sólo en virtud del propio Tratado constitucional. Sin embargo entiende el Gobierno que es preciso destacar que no se alteran las características jurídicas e institucionales básicas que definen el proyecto de integración europeo plasmado hoy en la Comunidad y en la Unión que conocemos. E igualmente debe subrayarse, pese a su obviedad, que el texto examinado es un tratado internacional, formal y materialmente, sin que pueda por ello negarse que tiene también, por su contenido general, muchas de las características propias de un texto constitucional. No se quiere afirmar con ello ?puntualiza el Gobierno? que un texto constitucional no puede surgir de un tratado, sino resaltar que la ratificación (art. IV47) y la revisión posterior del Tratado (arts. IV-43, IV-444 y IV-445) requieren la expresión unánime del consentimiento de todos los Estados miembros.

Tras una sucinta descripción del contenido de cada una de las cuatro partes del Tratado y de sus treinta y seis Protocolos el Gobierno destaca como características más destacadas del Tratado las siguientes:

1) La consolidación en un solo texto de los actuales Tratados de la Comunidad Europea y de la Unión Europea, con la consiguiente sistematización y simplificación de sus disposiciones principales, y la inclusión de una serie de nuevos preceptos de gran contenido político e institucional, especialmente en la parte I y en los capítulos de la parte III relativos al espacio de libertad, seguridad y justicia y la acción exterior de la Unión.

2) La integración en el Tratado de la Carta de derechos fundamentales de la Unión, dotándola de carácter jurídicamente vinculante, así como la inclusión de una cláusula habilitante que permitirá a la Unión adherirse como tal al Convenio europeo de derechos humanos, lo que someterá a la Unión Europea al control externo del Tribunal de Estrasburgo en materia de derechos humanos. 
3) La inscripción clara de ciertos principios fundamentales reguladores de las relaciones entre la Unión y los Estados miembros (principio de atribución de competencias, principio de cooperación leal, principio de primacía del Derecho de la Unión, principio del respeto a la identidad nacional de los Estados, etc.).

4) El reconocimiento de una personalidad jurídica única a la Unión Europea, facilitado por la "fusión" de los Tratados de la Comunidad Europea y de la Unión Europea en un solo texto y por la desaparición de la estructura de "pilares" creada por el Tratado de Maastricht de 1992.

5) La simplificación de los instrumentos y procedimientos de acción de la Unión, que se ordenan en actos legislativos (ley y ley marco europeas), actos no legislativos (reglamentos y decisiones europeos) y actos no obligatorios (recomendaciones y dictámenes).

6) La introducción de la posibilidad de que el legislativo comunitario (Consejo y Parlamento Europeos) confiera a la Comisión el poder de aprobar reglamentos delegados que completen o desarrollen elementos no esenciales de la ley o de la ley marco, dotándose así de una mayor agilidad al procedimiento normativo comunitario.

7) La generalización del actual procedimiento de codecisión como procedimiento legislativo ordinario, es decir, la necesidad, como regla general, del acuerdo del Consejo y del Parlamento Europeos para adoptar normas de Derecho derivado.

8) La clasificación de las competencias de la Unión en tres categorías: exclusivas, compartidas y medidas de apoyo. Destaca el Gobierno que, mientras que la lista de materias de las competencias exclusivas y la de las medidas de apoyo tienen carácter exhaustivo, la lista de las materias incluidas en las competencias compartidas es indicativa, definiéndose por oposición a todos aquellos ámbitos de actuación que no tienen carácter exclusivo ni de medidas de apoyo. Tanto el carácter no exhaustivo de las competencias compartidas como la subsistencia de una cláusula de flexibilidad (ex art. 308 TCE) serían una garantía mínima para permitir la evolución de la Unión y su adaptación a las nuevas necesidades de la realidad social y económica.

9) La previsión de un nuevo papel para los Parlamentos nacionales a la hora de verificar el cumplimiento del principio de subsidiariedad. Se explica en este punto que el Protocolo sobre la aplicación de los principios de subsi- 
diariedad y proporcionalidad contiene un mecanismo, coloquialmente denominado de "alerta temprana", de acuerdo con el cual todas las propuestas de naturaleza legislativa de la Comisión deben ser remitidas directamente a los Parlamentos nacionales, para que éstos puedan emitir un dictamen a la atención de la Comisión, del Consejo y del Parlamento Europeos. Si al menos un tercio de los Parlamentos nacionales (un cuarto en el caso de propuestas en el ámbito de los asuntos de justicia, libertad y seguridad) emitiera dictámenes motivados apreciando el incumplimiento del principio de subsidiariedad, la Comisión deberá reexaminar su propuesta. Por último, el Tribunal de Justicia es competente para conocer de los recursos por violación del principio de subsidiariedad interpuestos por los Estados miembros, a instancia, si procede, de sus Parlamentos nacionales, de acuerdo con sus respectivos ordenamientos constitucionales.

c) El Gobierno se extiende, a continuación, sobre la procedencia del presente requerimiento a la luz del Dictamen emitido por el Consejo de Estado el 21 de octubre de 2004. En dicho Dictamen, evacuado previa consulta del Gobierno de conformidad con el art. 22.1 de la Ley Orgánica 3/1980, de 22 de abril, del Consejo de Estado, la Comisión Permanente del Consejo realizó un detallado examen del Tratado desde la perspectiva de su compatibilidad con la Constitución española, analizando sus principales innovaciones.

El Consejo de Estado aprecia, en primer lugar, que se está ante un Tratado de integración supranacional que naturalmente encuentra su cauce de incorporación a nuestro Ordenamiento por la vía del art. $93 \mathrm{CE}$, precepto que, junto con otros de la Constitución, es expresión del designio de los constituyentes de abrir el Ordenamiento español a las influencias del Derecho internacional, pues a su través es posible verificar una transferencia del ejercicio de competencias derivadas de la Constitución a la Unión Europea. Por ello el Consejo de Estado pasa a analizar la suficiencia e idoneidad de ese cauce para ratificar el Tratado, concluyendo que, "aunque el sistema de atribución de competencias en los Tratados (cuya derogación producirá el ahora considerado) haya llevado a cuestionar la existencia de competencias suficientemente definidas como objeto de la atribución prevista en el artículo 93 de la Constitución, el nuevo sistema recogido en el Tratado clarifica y precisa el marco competencial de la Unión, reduciendo, en consecuencia, el amplio margen de interpretación que los Tratados han permitido hasta ahora". Por ello el Consejo de Estado considera idóneo el cauce del art. 93 CE para ratificar el Tratado.

Por lo que hace a la parte II del Tratado, en la que se integra, con pleno valor jurídico, la Carta de derechos fundamentales de la Unión Europea, el 
Consejo de Estado constata que su significado debe ponderarse a partir de la base de que las disposiciones de la Carta limitan su fuerza vinculante para los Estados miembros "únicamente cuando apliquen el Derecho de la Unión" (apartado 1 del artículo II-111), delimitación que se une a la declaración de que ni la Carta ni el Convenio europeo implican ampliación alguna de las competencias atribuidas a la Unión. Además el artículo II-113 impide, en un sentido similar al del artículo 53 del Convenio europeo, que las disposiciones de la Carta puedan interpretarse como limitativas o lesivas de los derechos humanos y libertades fundamentales reconocidos, en su respectivo ámbito de aplicación, por el Derecho de la Unión, el Derecho internacional y los convenios internacionales de los que son parte la Unión o todos los Estados miembros y, en particular, el Convenio europeo para la protección de los derechos humanos y de las libertades fundamentales, así como por las Constituciones de los Estados miembros. Por su lado el artículo II-112 precisa, respecto de los derechos contenidos en la Carta que correspondan a derechos garantizados por el Convenio europeo, que "su sentido y alcance serán iguales a los que les confiere dicho Convenio", sin que obste a "que el Derecho de la Unión conceda una protección más extensa” (apartado 3), y añade que los derechos reconocidos por la Carta resultantes de las tradiciones constitucionales comunes a los Estados miembros "se interpretarán en armonía con las citadas tradiciones" (apartado 4).

De lo anterior concluye el Consejo de Estado que parece quedar garantizado "suficientemente que las disposiciones de la Carta no van a producir colisiones o discordancias con la configuración que la Constitución Española hace de esos derechos y libertades". Ahora bien, la coexistencia de dos sistemas de garantías con el establecido en el Convenio Europeo, al que expresamente se refiere también la Carta, supone la coexistencia de tres regímenes o parámetros en la tutela de los derechos fundamentales (Constitución, Convenio europeo y Carta) que determinará en el futuro, si el Tratado entra en vigor, un proceso de influencias mutuas no exento de problemas jurídicos que el Consejo de Estado considera corresponde aclarar al Tribunal Constitucional en lo que se refiere al sentido de la vinculación de las autoridades españolas por la Carta, las relaciones de ésta con nuestro sistema constitucional de derechos y libertades y el modo de depuración de las normas que la contradigan. Cuestiones todas ellas que justifican la duda de constitucionalidad que ahora plantea el Gobierno.

Examina, en tercer lugar, el Consejo de Estado el estatuto de la ciudadanía europea a la luz del nuevo Tratado (título II de la parte I y título V de la parte II), destacando que, "abstracción hecha de los desajustes sistemáticos 
que pueden inferirse ... es lo cierto que al contenido básico de la ciudadanía europea ya verificó su apertura el ordenamiento español y los nuevos derechos están referidos al ámbito de actuación de los poderes de la Unión y se sitúan en plena consonancia con los derechos de los administrados según las tradiciones constitucionales de los Estados miembros". Y en lo que se refiere al ámbito subjetivo de aplicación del mencionado estatuto de ciudadanía el Consejo de Estado destaca que la ciudadanía de la Unión "se añade a la ciudadanía nacional sin sustituirla ni interferirla en la formulación actual de la Constitución Española, por lo que no parece que plantee problemas el acoplamiento de dichas previsiones con el ordenamiento nacional".

Por último el Consejo de Estado analiza la proclamación explícita y formal en el artículo I-6 del principio de primacía del Derecho de la Unión, cuestionándose sobre el posible conflicto entre ese precepto y la Constitución. Señala el Consejo de Estado que "el Tratado eleva a norma de la Constitución para Europa la primacía del Derecho comunitario. Dicho principio, que se ha calificado como una 'exigencia existencial' de tal Derecho, como se sabe, es fruto de la construcción jurisprudencial del Tribunal de Justicia de las Comunidades Europeas a partir de la Sentencia de 15 de julio de 1964 (Costa c. ENEL) y desarrollado en pronunciamientos posteriores, así las SSTJCE de 14 de diciembre de 1971 (Politi), 13 de julio de 1972 (Comisión c. Italia), 9 de marzo de 1978 (Simenthal), entre otras muchas, y significa que cualquier norma del Derecho comunitario, no sólo del primario, sino también del derivado, prevalece sobre las de Derecho interno, cualquiera que sea el rango de éstas, incluido el constitucional. Opera, pues, contra cualquier fuente, ya sea anterior o posterior al Derecho comunitario y respecto tanto de los órganos jurisdiccionales como del resto de los órganos del Estado".

El Consejo de Estado entiende, a la luz de lo anterior, que la redacción del artículo I-6 del nuevo Tratado de la Unión puede chocar con la consideración de la Constitución Española como norma suprema de nuestro Ordenamiento jurídico y recomienda, a este respecto, que se haga uso de la facultad prevista en el art. 95.2 CE para que el Tribunal Constitucional declare si existe o no contradicción entre el Tratado por el que se establece una Constitución para Europa y la propia Constitución española.

Para el caso de que la existencia de dicha contradicción así fuera apreciada en relación con esa cuestión concreta, el Consejo de Estado apunta, como posible fórmula para salvar en este caso y pro futuro eventuales problemas de compatibilidad entre la Constitución y el Derecho comunitario, que "quizás mejor que proceder a reformas materiales puntuales cada vez que se de- 
tecte una colisión, sería, siguiendo la pauta de otros modelos constitucionales europeos, introducir en la propia Constitución (a.e., con una reformulación del artículo 93) una cláusula de integración que incorpore un mecanismo que por sí solo y en sí mismo permita con los límites de intangibilidad que se estimen irrenunciables, con los objetivos o con los requisitos formales agravados que se consideren necesarios? una apertura general del ordenamiento español al Derecho comunitario y, en su virtud, se reconozca apriorísticamente la constitucionalidad ?la compatibilidad con la Constitución? de dicho ordenamiento".

A la vista de la recomendación formulada por el Consejo de Estado y las consideraciones y opiniones antes expuestas el Gobierno ha adoptado el acuerdo de requerir de este Tribunal Constitucional la Declaración de que ha quedado constancia.

3. Mediante providencia de 8 de noviembre de 2004 el Pleno acordó tener por recibido el requerimiento formulado por el Gobierno de la Nación al amparo de los arts. 95.2 de la Constitución y 78.1 LOTC, y emplazar, conforme a lo dispuesto en el art. 78.2 LOTC, al propio Gobierno, al Congreso de los Diputados y al Senado, por conducto de sus respectivos Presidentes, a fin de que, dentro del término máximo de un mes, expresaran su opinión fundada sobre la cuestión.

4. Mediante escrito registrado en el Tribunal el 18 de noviembre de 2004 el Presidente del Senado dio traslado a este Tribunal del Acuerdo adoptado por la Mesa de la Cámara el 16 de noviembre de 2004, en el que, dando por recibida la comunicación de la providencia de 8 de noviembre anterior, se manifiesta que la Cámara Alta no ejercerá su derecho a emitir opinión fundada sobre la cuestión objeto del requerimiento planteado por el Gobierno.

5. Por escrito registrado en este Tribunal el 19 de noviembre de 2004 el Presidente del Congreso de los Diputados dio traslado del Acuerdo de la Mesa de la Cámara de 15 de noviembre de 2004, por el que se comunica a este Tribunal que el Congreso de los Diputados no se personará en este procedimiento ni expresará su opinión fundada sobre la cuestión, remitiendo a la Dirección de Estudios y Documentación de la Secretaría General.

6. Por escrito registrado el 19 de noviembre de 2004, del que se dio cuenta por diligencia de la Secretaria de Justicia del Pleno del día 22 siguiente, el Abogado del Estado, en la representación que legalmente ostenta y en cum- 
plimiento de las instrucciones contenidas en el Acuerdo del Consejo de Ministros de 19 de noviembre de 2004, declara que el Gobierno de la Nación no formulará opinión fundada en el trámite del art. 78.2 LOTC, remitiéndose al texto del Acuerdo del Gobierno que dio lugar a la iniciación del presente procedimiento.

\section{Fundamentos jurídicos}

1. Es ésta la segunda ocasión en que este Tribunal es requerido para pronunciarse sobre la conformidad con la Constitución de un tratado internacional que se pretende integrar en el Ordenamiento español, en este caso el Tratado por el que se establece una Constitución para Europa. Requerimiento que ha de sustanciarse a través del específico cauce procesal previsto en el art. 95.2 de la Constitución y regulado en el art. 78 de la Ley Orgánica de este Tribunal (LOTC); sobre cuya naturaleza y sentido hicimos ya en la Declaración 1/1992, de 1 de julio (DTC 1/1992, en adelante), una serie de consideraciones que conviene recordar ahora.

Se dijo entonces, en efecto, que con el procedimiento establecido en el art. 95.2 de la Constitución se confía a este Tribunal un doble cometido, pues al general o común, consistente en la defensa jurisdiccional de la Constitución, se suma el de garantizar la seguridad y estabilidad de los compromisos internacionales que España pueda contraer. Si se prefiere, al cometido jurisdiccional propio de este Tribunal se le añade, en virtud de su ejercicio preventivo, una dimensión cautelar al servicio de la salvaguardia de la responsabilidad internacional del Estado. Se trata, en definitiva, de asegurar la supremacía de la Constitución sin perjuicio alguno para esos compromisos, procurando evitar que la posible contradicción entre una y otros haya de resolverse una vez integradas en el Ordenamiento las normas pactadas; esto es, cuando de la lógica de la supremacía de la Constitución puedan derivar consecuencias incompatibles con la lógica del respeto a lo internacionalmente acordado. El art. 95.2 CE hace posible que las dudas de constitucionalidad que pueda suscitar un tratado se resuelvan con carácter previo a su ratificación, de manera que, de confirmarse aquéllas, ésta queda impedida en tanto no se revise el texto constitucional o se renegocie el tratado en términos que lo hagan compatible con la Constitución. Se pretende evitar, en suma, que la contradicción advertida entre la Norma suprema, de un lado, y una norma todavía no integrada en el sistema regido por aquélla, de otro, llegue a sustanciarse en una contradicción entre la Constitución y una norma internacional incorporada a nuestro Ordenamiento. 
Con esta defensa jurisdiccional anticipada la Constitución ve asegurada su supremacía frente a las normas internacionales desde el momento mismo de la integración de éstas en el Derecho nacional, tratándose de obviar "la perturbación que, para la política exterior y las relaciones internacionales del Estado, implicaría la eventual declaración de inconstitucionalidad de una norma pactada" (DTC 1/1992, de 1 de julio, FJ 1) si el juicio de contraste se verificase una vez que hubiera sido ya incorporada al Ordenamiento interno. La contradicción se resuelve, por tanto, evitándola en su origen, y no sólo cuando, ya producida, no queda otro expediente que el de la activación de dos sistemas de garantía, el internacional y el interno [ex art. 27.2 c) LOTC], que pueden abocar a consecuencias mutuamente perturbadoras.

Por ello, en razón de la naturaleza estrictamente jurisdiccional del procedimiento preventivo contemplado en el art. 95.2 de la Constitución, en la citada Declaración 1/1992 hemos dicho que "lo que de nosotros puede solicitarse es una declaración, no un dictamen; una decisión, no una mera opinión fundada en Derecho, [pues] este Tribunal no deja de serlo para transformarse ocasionalmente, por obra del requerimiento, en cuerpo consultivo. Lo que el requerimiento incorpora es, al igual que acontece en las cuestiones de inconstitucionalidad, la exposición de una duda razonable, pero lo que de nosotros se solicita no es un razonamiento que la resuelva, sino una decisión vinculante" (DTC 1/1992, FJ 1). Y es esa naturaleza jurisdiccional la que impone que nuestro pronunciamiento sólo pueda fundamentarse en argumentaciones jurídico-constitucionales sugeridas o no por quien requiere o por quienes pueden comparecer en el procedimiento y "ceñirse ... al contraste entre la Constitución, en cualquiera de sus enunciados, y la estipulación o estipulaciones del tratado que hayan sido sometidas a control previo, pues el art. $95.1 \mathrm{de}$ aquélla ha reservado en exclusiva al Gobierno y a una u otra de ambas Cámaras la facultad de formular esta duda de constitucionalidad, cuyo planteamiento y elucidación ex officio no le corresponde, por tanto, al Tribunal, el cual, al igual que en los demás procedimientos, carece de iniciativa, y está vinculado al principio constitucional de congruencia. Ello sin perjuicio de que este Tribunal pueda solicitar nuevas informaciones y aclaraciones o ampliaciones de conformidad con el art. 78.3 LOTC." (loc. ult. cit.)

2. La duda de constitucionalidad planteada por el Gobierno de la Nación se refiere a tres preceptos del Tratado por el que se establece una Constitución para Europa, firmado en Roma el 29 de octubre de 2004, los artículos I6, II-111 y II-112. Además el Gobierno requiere a este Tribunal para que se pronuncie sobre la suficiencia del art. $93 \mathrm{CE}$ para dar cauce a la integración del Tratado en el Ordenamiento interno o, en su caso, sobre el procedimien- 
to de revisión constitucional pertinente para adecuar la Constitución al Tratado con anterioridad a su integración.

Antes de dar respuesta pormenorizada a las cuestiones planteadas son precisas algunas consideraciones previas sobre el alcance y contenido del art. 93 CE, cuya puesta en juego constituye de por sí una aplicación de la Constitución misma, exponente, a su vez, de un inequívoco acto de ejercicio de la soberanía de España.

Tal y como se desprende de los trabajos de las Cortes constituyentes, el art. 93 se concibió como el medio constitucional de nuestra integración en las Comunidades europeas, fenómeno de integración que va más allá del puro procedimiento de la misma, y que comporta las consecuencias de la inserción en un ente supranacional distinto, susceptible de crear un Ordenamiento propio dotado de particulares principios rectores de la eficacia y de las exigencias y límites de la aplicabilidad de sus normas. Aquella fue una integración largamente anhelada y, sin ninguna duda, constitucionalmente querida y por ello facilitada por el citado art. $93 \mathrm{CE}$.

La adhesión del Reino de España a la hoy Unión Europea se ha instrumentado en efecto a través del art. 93 de nuestra Constitución, precepto clave, en consecuencia, a tal fin, que este Tribunal ha procedido ya a caracterizar en su jurisprudencia y en su anterior DTC $1 / 1992$, y en cuya complejidad, que en dicha Declaración ya anunciamos que "no es leve" (FJ 4), hemos de seguir ahondando para dar respuesta al requerimiento que ahora se nos formula.

Del art. $93 \mathrm{CE}$, "fundamento último" de nuestra incorporación al proceso de integración europea y de nuestra vinculación al Derecho comunitario, hemos dicho que se trata de un precepto "de índole orgánico procedimental" (STC 28/1991, de 14 de febrero, FJ 4, y DTC 1/1992, FJ 4) en cuya virtud es posible la atribución del ejercicio de competencias derivadas de la Constitución a organizaciones o instituciones internacionales. Tal dimensión fue la única considerada en la citada Declaración tan sólo a fin de determinar, en respuesta a la duda planteada entonces, si el art. $93 \mathrm{CE}$ era mecanismo adecuado para excepcionar el límite que el art. 13.2 CE establecía a la extensión a los extranjeros por tratado o por ley del derecho de sufragio pasivo en las elecciones municipales, concluyéndose ante la contradicción atinente al texto de una norma constitucional sustantiva que dicho precepto no incorpora un cauce revisorio equiparable a los procedimientos de reforma constitucional regulados en el Título X CE. Pero sí es el cauce previsto por la Constitución para transferir o atribuir a organizaciones o instituciones internacionales el 
ejercicio de competencias derivadas de la misma, modulándose así, por tanto, como reconocimos en aquella Declaración, el ámbito de aplicación y ordenación del ejercicio de las competencias cedidas (FJ 4).

Ahora bien, lo que dijimos en la DTC 1/1992 se situaba en unas coordenadas precisas, consistentes entonces en la existencia de una contradicción entre el art. 8.B del Tratado constitutivo de la Comunidad Europea y el texto de la Constitución española, su art. 13.2, siendo en esas coordenadas en las que debe entenderse el alcance de algunos de los contenidos de dicha Declaración a la hora de emitir la actual, que opera en un marco bien distinto, en el que, como razonaremos, tal contradicción con el texto no se da.

El art. 93 CE es sin duda soporte constitucional básico de la integración de otros ordenamientos con el nuestro, a través de la cesión del ejercicio de competencias derivadas de la Constitución, ordenamientos llamados a coexistir con el Ordenamiento interno, en tanto que ordenamientos autónomos por su origen. En términos metafóricos podría decirse que el art. $93 \mathrm{CE}$ opera como bisagra mediante la cual la Constitución misma da entrada en nuestro sistema constitucional a otros ordenamientos jurídicos a través de la cesión del ejercicio de competencias. De este modo se confiere al art. $93 \mathrm{CE}$ una dimensión sustantiva o material que no cabe ignorar.

Producida la integración debe destacarse que la Constitución no es ya el marco de validez de las normas comunitarias, sino el propio Tratado cuya celebración instrumenta la operación soberana de cesión del ejercicio de competencias derivadas de aquélla, si bien la Constitución exige que el Ordenamiento aceptado como consecuencia de la cesión sea compatible con sus principios y valores básicos.

Como se deriva del mecanismo contenido en el propio precepto constitucional, tampoco cabe ignorar la necesidad de proporcionar a los organismos internacionales en cuyo favor se ha cedido el ejercicio de las competencias los instrumentos indispensables para garantizar el cumplimiento del Derecho por ellos creado, función que sólo puede verse obstaculizada por un entendimiento inadecuado del citado precepto constitucional y de su sustancia integracionista. De ahí que sea imprescindible una interpretación que atienda a la insoslayable dimensión de integración comunitaria que el precepto constitucional comporta.

Esa interpretación debe partir del reconocimiento de que la operación de cesión del ejercicio de competencias a la Unión europea y la integración con- 
siguiente del Derecho comunitario en el nuestro propio imponen límites inevitables a las facultades soberanas del Estado, aceptables únicamente en tanto el Derecho europeo sea compatible con los principios fundamentales del Estado social y democrático de Derecho establecido por la Constitución nacional. Por ello la cesión constitucional que el art. 93 CE posibilita tiene a su vez límites materiales que se imponen a la propia cesión. Esos límites materiales, no recogidos expresamente en el precepto constitucional, pero que implícitamente se derivan de la Constitución y del sentido esencial del propio precepto, se traducen en el respeto de la soberanía del Estado, de nuestras estructuras constitucionales básicas y del sistema valores y principios fundamentales consagrados en nuestra Constitución, en el que los derechos fundamentales adquieren sustantividad propia (art. 10.1 CE), límites que, como veremos después, se respetan escrupulosamente en el Tratado objeto de nuestro análisis.

Hechas estas consideraciones, procede ya pasar a responder directamente las preguntas planteadas por el Gobierno.

3. La primera cuestión se refiere al artículo I-6 del Tratado, cuyo tenor literal es el siguiente:

"La Constitución y el Derecho adoptado por las instituciones de la Unión en el ejercicio de las competencias que se le atribuyen a ésta primarán sobre el Derecho de los Estados miembros".

Esta estipulación del Tratado, tal y como ha hecho constar formalmente la Conferencia de los Representantes de los Gobiernos de los Estados Miembros por medio de Declaración anexa al Tratado (Declaración anexa al art. I6), "refleja la jurisprudencia existente del Tribunal de Justicia de las Comunidades Europeas y del Tribunal de Primera Instancia", y en su expresa proclamación acota la primacía del Derecho de la Unión al ámbito del ejercicio de las competencias atribuidas a las instituciones europeas. Tal primacía no se afirma como superioridad jerárquica sino como una "exigencia existencial" de ese Derecho, a fin de lograr en la práctica el efecto directo y la aplicación uniforme en todos los Estados. Las coordenadas que así se establecen para la definición del ámbito de vigencia de ese principio son, como veremos, determinantes para su entendimiento a la luz de las categorías constitucionales que nos son propias.

El primer aspecto a destacar, para interpretar correctamente la primacía proclamada y el marco en que se desenvuelve, es que el Tratado por el que se establece una Constitución para Europa parte del respeto a la identidad de 
los Estados integrados en ella y de sus estructuras constitucionales básicas, y se funda en los valores que están en la base de las Constituciones de dichos Estados.

Es al respecto suficientemente explícito el art. I-5.1, cuando dice:

"La Unión respetará la igualdad de los Estados miembros ante la Constitución, así como su identidad nacional, inherente a las estructuras políticas y constitucionales de éstos, también en lo referente a la autonomía local y regional. Respetará las funciones esenciales del Estado, especialmente las que tienen por objeto garantizar su integridad territorial, mantener el orden público y salvaguardar la seguridad nacional”.

Al propio tiempo, por lo que concierne a los valores que fundamentan la Unión, es terminante el art. I-2, que dispone al respecto:

"La Unión se fundamenta en los valores de la dignidad humana, libertad, democracia, igualdad, Estado de Derecho y respeto de los Derechos humanos, incluidos los derechos de las personas pertenecientes a minorías. Estos valores son comunes a los Estados miembros en una sociedad caracterizada por el pluralismo, la no discriminación, la tolerancia, la justicia, la solidaridad y la igualdad entre mujeres y hombres".

Lo que, a su vez, tiene su continuidad normativa en la Carta de los derechos fundamentales de la Unión, contenida en la parte segunda del Tratado, cuyo preámbulo afirma que "está fundada sobre los valores indivisibles de la dignidad humana, la libertad, la igualdad y la solidaridad", y ninguna de cuyas disposiciones "podrá interpretarse como limitativa o lesiva de los derechos humamos y libertades fundamentales reconocidos ... por las constituciones de los Estados miembros" (art. II-113 del Tratado).

Dichos preceptos, entre otros, vienen a consagrar la garantía de la existencia de los Estados y sus estructuras básicas, así como sus valores, principios y derechos fundamentales, que en ningún caso podrían llegar a hacerse irreconocibles tras el fenómeno de la cesión del ejercicio de competencias a la organización supraestatal, garantía cuya ausencia o cuya falta de una proclamación explícita justificó en etapas anteriores las reservas opuestas a la primacía del Derecho comunitario frente a las distintas Constituciones por conocidas decisiones de las jurisdicciones constitucionales de algunos Estados, en lo que ha dado en llamarse en la doctrina el diálogo entre los tribunales constitucionales y el Tribunal de Justicia de las Comunidades Europeas. En otros térmi- 
nos, los límites a que se referían las reservas de dichas jurisdicciones constitucionales aparecen ahora proclamados de modo inequívoco por el propio Tratado sometido a nuestra consideración, que ha venido a acomodar sus disposiciones a las exigencias de las Constituciones de los Estados miembros.

Así pues la primacía que se proclama en el Tratado por el que se establece una Constitución para Europa opera respecto de un Ordenamiento que se construye sobre los valores comunes de las Constituciones de los Estados integrados en la Unión y de sus tradiciones constitucionales.

Sobre la base de esas garantías debe destacarse además que la primacía que para el Tratado y su Derecho derivado se establece en el cuestionado art. I-6 se contrae expresamente al ejercicio de las competencias atribuidas a la Unión Europea. No es, por tanto, una primacía de alcance general, sino referida exclusivamente a las competencias propias de la Unión. Tales competencias están delimitadas con arreglo al principio de atribución (art. I-11.1 del Tratado), en cuya virtud "la Unión actúa dentro de los límites de las competencias que le atribuyen los Estados miembros en la Constitución [europea] para lograr los objetivos que ésta determina" (art. I-11.2). La primacía opera, por tanto, respecto de competencias cedidas a la Unión por voluntad soberana del Estado y también soberanamente recuperables a través del procedimiento de "retirada voluntaria" previsto en el artículo I-60 del Tratado.

$\mathrm{Al}$ propio tiempo se ha de destacar que la Unión debe ejercer sus competencias no exclusivas de conformidad con los principios de subsidiariedad y proporcionalidad (art. I-11.3 y 4), de manera que se racionaliza y limita el fenómeno de la expansividad competencial, propiciada anteriormente por la naturaleza funcional y dinámica del Derecho comunitario, pues en lo sucesivo, y en virtud de la "cláusula de flexibilidad" tal y como es hoy recogida en el artículo I-18 del Tratado, a falta de poderes específicos para emprender acciones necesarias para la consecución de sus objetivos, la Unión sólo podrá actuar a través de medidas adoptadas por el Consejo de Ministros, por unanimidad, a propuesta de la Comisión y previa aprobación del Parlamento Europeo, previéndose la participación de los Parlamentos nacionales en el marco del procedimiento de control del principio de subsidiariedad mencionado en el artículo I-11.3 del Tratado.

Y por lo que hace al modo de distribución de competencias entre la Unión Europea y los Estados miembros, los artículos I-12 a I-17 del Tratado definen con mayor precisión el ámbito competencial propio de la Unión. En consecuencia el nuevo Tratado no altera sustancialmente la situación creada 
tras nuestra adhesión a las Comunidades y, si acaso, la simplifica y reordena en términos que hacen más preciso el alcance de la cesión del ejercicio de competencias verificada por España. Pero, sobre todo, se advierte que las competencias cuyo ejercicio se transfiere a la Unión Europea no podrían, sin quiebra del propio Tratado, servir de fundamento para la producción de normas comunitarias cuyo contenido fuera contrario a valores, principios o derechos fundamentales de nuestra Constitución.

4. Definidos los elementos esenciales del marco normativo en el que se sitúa el precepto sobre el que se proyectan las dudas del Gobierno, debe destacarse que éste hace suyas las dudas expresadas por el Consejo de Estado en su Dictamen de 21 de octubre de 2004 acerca de la compatibilidad de este artículo con la Constitución, identificando como posible precepto constitucional contradicho su art. 9.1, que proclamaría un principio de supremacía de la Constitución sobre el que se fundamenta el título IX de la Norma fundamental ("Del Tribunal Constitucional") y cuya garantía se procura con las previsiones del título X ("De la reforma constitucional"). En realidad, atendidos los términos en que se plantea la cuestión, la contradicción advertida no podría dejar de extenderse al propio art. 1.2 de la Constitución, pues la supremacía pretendidamente puesta en riesgo por el Tratado se predica de una Norma que la disfruta, en tanto que expresión del ejercicio de la voluntad constituyente del Estado por el pueblo español, en quien reside la soberanía nacional.

No obstante, de inmediato veremos que tal contradicción no existe.

Que la Constitución es la norma suprema del Ordenamiento español es cuestión que, aun cuando no se proclame expresamente en ninguno de sus preceptos, se deriva sin duda del enunciado de muchos de ellos, entre otros de sus arts. 1.2, 9.1, 95, 161, 163, 167, 168 y disposición derogatoria, y es consustancial a su condición de norma fundamental; supremacía o rango superior de la Constitución frente a cualquier otra norma, y en concreto frente a los tratados internacionales, que afirmamos en la Declaración 1/1992 (FJ 1). Pues bien, la proclamación de la primacía del Derecho de la Unión por el art. I-6 del Tratado no contradice la supremacía de la Constitución.

Primacía y supremacía son categorías que se desenvuelven en órdenes diferenciados. Aquélla, en el de la aplicación de normas válidas; ésta, en el de los procedimientos de normación. La supremacía se sustenta en el carácter jerárquico superior de una norma y, por ello, es fuente de validez de las que le están infraordenadas, con la consecuencia, pues, de la invalidez de éstas si 
contravienen lo dispuesto imperativamente en aquélla. La primacía, en cambio, no se sustenta necesariamente en la jerarquía, sino en la distinción entre ámbitos de aplicación de diferentes normas, en principio válidas, de las cuales, sin embargo, una o unas de ellas tienen capacidad de desplazar a otras en virtud de su aplicación preferente o prevalente debida a diferentes razones. Toda supremacía implica, en principio, primacía (de ahí su utilización en ocasiones equivalente, así en nuestra Declaración 1/1992, FJ 1), salvo que la misma norma suprema haya previsto, en algún ámbito, su propio desplazamiento o inaplicación. La supremacía de la Constitución es, pues, compatible con regímenes de aplicación que otorguen preferencia aplicativa a normas de otro Ordenamiento diferente del nacional siempre que la propia Constitución lo haya así dispuesto, que es lo que ocurre exactamente con la previsión contenida en su art. 93, mediante el cual es posible la cesión de competencias derivadas de la Constitución a favor de una institución internacional así habilitada constitucionalmente para la disposición normativa de materias hasta entonces reservadas a los poderes internos constituidos y para su aplicación a éstos. En suma, la Constitución ha aceptado, ella misma, en virtud de su art. 93, la primacía del Derecho de la Unión en el ámbito que a ese Derecho le es propio, según se reconoce ahora expresamente en el art. I-6 del Tratado.

Y así han sido las cosas entre nosotros desde la incorporación de España a las Comunidades Europeas en 1986. Entonces se integró en el Ordenamiento español un sistema normativo autónomo, dotado de un régimen de aplicabilidad específico, basado en el principio de prevalencia de sus disposiciones propias frente a cualesquiera del orden interno con las que pudieran entrar en contradicción. Ese principio de primacía, de construcción jurisprudencial, formaba parte del acervo comunitario incorporado en virtud de la Ley Orgánica 10/1985, de 2 de agosto, de autorización para la adhesión de España a las Comunidades Europeas, pues se remonta a la doctrina iniciada por el Tribunal de Justicia de las Comunidades con la Sentencia de 15 de julio de 1964 (Costa contra ENEL).

Por lo demás nuestra jurisprudencia ha venido reconociendo pacíficamente la primacía del Derecho comunitario europeo sobre el interno en el ámbito de las "competencias derivadas de la Constitución", cuyo ejercicio España ha atribuido a las instituciones comunitarias con fundamento, como hemos dicho, en el art. $93 \mathrm{CE}$.

En concreto nos hemos referido expresamente a la primacía del Derecho comunitario como técnica o principio normativo destinado a asegurar su efectividad en nuestra STC 28/1991, de 14 de febrero, FJ 6, con reproducción par- 
cial de la Sentencia Simmenthal del Tribunal de Justicia, de 9 de marzo de 1978, y en la posterior STC 64/1991, de 22 de marzo, FJ 4 a). En nuestras posteriores SSTC 130/1995, de 11 de septiembre, FJ 4, 120/1998, de 15 de junio, FJ 4, y 58/2004, de 19 de abril, FJ 10, reiteramos el reconocimiento de esa primacía de las normas del Ordenamiento comunitario, originario y derivado, sobre el interno, y su efecto directo para los ciudadanos, asumiendo la caracterización que de tal primacía y eficacia había efectuado el Tribunal de Justicia, entre otras, en sus conocidas y ya antiguas Sentencias Vand Gend en Loos, de 5 de febrero de 1963, y Costa contra ENEL, de 15 de julio de 1964, ya citada.

Así pues, en razón de lo dicho, ha de concluirse que, con base en lo dispuesto en el art. $93 \mathrm{CE}$, correctamente entendido, y dadas las concretas previsiones del Tratado ya señaladas en el fundamento jurídico precedente, este Tribunal no aprecia contradicción entre el art. I-6 del Tratado y el art. 9.1 CE, no dándose, en definitiva, el supuesto normativo del art. 95.1 CE.

En el caso difícilmente concebible de que en la ulterior dinámica del Derecho de la Unión Europea llegase a resultar inconciliable este Derecho con la Constitución española, sin que los hipotéticos excesos del Derecho europeo respecto de la propia Constitución europea fueran remediados por los ordinarios cauces previstos en ésta, en última instancia la conservación de la soberanía del pueblo español y de la supremacía de la Constitución que éste se ha dado podrían llevar a este Tribunal a abordar los problemas que en tal caso se suscitaran, que desde la perspectiva actual se consideran inexistentes, a través de los procedimientos constitucionales pertinentes, ello aparte de que la salvaguarda de la referida soberanía siempre resulta a la postre asegurada por el art. I-60 del Tratado, verdadero contrapunto de su art. I-6, y que permite definir en su real dimensión la primacía proclamada en este último, incapaz de sobreponerse al ejercicio de una renuncia, que queda reservada a la voluntad soberana, suprema, de los Estados miembros.

5. El Gobierno requiere también una declaración sobre la posible contradicción con la Constitución de dos estipulaciones del Tratado incluidas en el título VII de su parte II y referidas al ámbito de aplicación y al alcance e interpretación de los derechos y principios de la Carta de los derechos fundamentales de la Unión, proclamada en Niza el 7 de diciembre de 2000 y ahora incorporada al Tratado. El primero de los preceptos sobre los que inquiere el Gobierno es el artículo II-111, en cuya virtud:

"1. Las disposiciones de la presente Carta están dirigidas a las instituciones, órganos y organismos de la Unión, dentro del respeto del principio 
de subsidiariedad, así como a los Estados miembros únicamente cuando apliquen el Derecho de la Unión. Por consiguiente, éstos respetarán los derechos, observarán los principios y promoverán su aplicación, con arreglo a sus respectivas competencias y dentro de los límites de las competencias que se atribuyen a la Unión en las demás Partes de la Constitución.

2. La presente Carta no amplía el ámbito de aplicación del Derecho de la Unión más allá de las competencias de la Unión, ni crea ninguna competencia o misión nuevas para la Unión, ni modifica las competencias y misiones definidas en las demás Partes de la Constitución”.

La segunda de las estipulaciones señaladas por el Gobierno, el artículo II112, prescribe:

"1. Cualquier limitación del ejercicio de los derechos y libertades reconocidos por la presente Carta deberá ser establecida por la ley y respetar el contenido esencial de dichos derechos y libertades. Dentro del respeto del principio de proporcionalidad, sólo podrán introducirse limitaciones cuando sean necesarias y respondan efectivamente a objetivos de interés general reconocidos por la Unión o a la necesidad de protección de los derechos y libertades de los demás.

2. Los derechos reconocidos por la presente Carta que se mencionan en otras Partes de la Constitución se ejercerán en las condiciones y dentro de los límites definidos por ellas.

3. En la medida en que la presente Carta contenga derechos que correspondan a derechos garantizados por el Convenio Europeo para la Protección de los Derechos Humanos y de las Libertades Fundamentales, su sentido y alcance serán iguales a los que les confiere dicho Convenio. Esta disposición no obstará a que el Derecho de la Unión conceda una protección más extensa.

4. En la medida en que la presente Carta reconozca derechos fundamentales resultantes de las tradiciones constitucionales comunes a los Estados miembros, dichos derechos se interpretarán en armonía con las citadas tradiciones.

5. Las disposiciones de la presente Carta que contengan principios podrán aplicarse mediante actos legislativos y ejecutivos adoptados por las 
instituciones, órganos y organismos de la Unión, y por actos de los Estados miembros cuando apliquen el Derecho de la Unión, en el ejercicio de sus competencias respectivas. Sólo podrán alegarse ante un órgano jurisdiccional en lo que se refiere a la interpretación y control de la legalidad de dichos actos.

6. Se tendrán plenamente en cuenta las legislaciones y prácticas nacionales según lo especificado en la presente Carta.

7. Las explicaciones elaboradas para guiar en la interpretación de la Carta de los Derechos Fundamentales serán tenidas debidamente en cuenta por los órganos jurisdiccionales de la Unión y de los Estados miembros".

El Gobierno entiende, haciendo suyo también aquí el parecer del Consejo de Estado, que las estipulaciones de la Carta no entran en colisión con la configuración constitucional de los derechos y libertades, máxime si se tiene en cuenta la invocación del Convenio europeo para la protección de los derechos humanos y de las libertades fundamentales por parte del artículo II112.3 del Tratado, pues la común remisión del Tratado y del art. 10.2 de la Constitución a ese Convenio supone la conformidad sustancial de la parte II del Tratado con el orden de valores, derechos y principios garantizados por la Constitución Española. Si alguna dificultad se advierte por el Gobierno sería la que resulta de la coexistencia de tres regímenes de tutela de los derechos fundamentales (Constitución, Convenio europeo y Carta), que necesariamente determinará un proceso de influencias mutuas no exento de dificultades. En particular el Consejo de Estado advierte en su dictamen que corresponderá a este Tribunal Constitucional "aclarar el sentido de la vinculación de las autoridades españolas por la Carta, las relaciones de ésta con nuestro sistema constitucional de derechos y libertades y el modo de depuración de las normas que la contradigan".

En el Acuerdo del Consejo de Ministros por el que se ha dispuesto plantear el presente requerimiento parece interpretarse la anterior consideración del Consejo de Estado en el sentido de que es precisamente en el marco de este procedimiento del art. 95.2 CE donde procedería una respuesta de este Tribunal a los problemas que resultarían de la coexistencia de tres regímenes de garantía de los derechos y libertades fundamentales. Con todo la concreta cuestión planteada por el Gobierno se ciñe a la compatibilidad de los artículos II-111 y II-112 del Tratado con la Constitución "a la vista de lo establecido en el artículo 10.2 de la Constitución Española”. Sobre la base de todo ello la duda gubernamental a la que aquí puede darse respuesta alcanza únicamente 
a la compatibilidad con la Constitución de un sistema de derechos que, por obra de la remisión contenida en el art. 10.2 de la Constitución, se erigiría, tras su integración, en parámetro determinante de la configuración de los derechos y libertades, acaso no sólo en el ámbito propio del Derecho europeo, sino, por su inherente vocación expansiva, también en el puramente interno.

6. Los problemas de articulación entre regímenes de garantía son característicos de nuestro sistema de derechos fundamentales, correspondiendo a este Tribunal Constitucional la función de precisar el concreto contenido de los derechos y libertades asegurados por el poder público español a partir de la concurrencia, en su definición, de normas internacionales y normas estrictamente internas, dotadas las primeras de instancias propias de protección y, por tanto, de definición autorizada de su contenido y alcance. Los concretos problemas de articulación que pudieran suscitarse con la integración del Tratado no pueden ser objeto de un pronunciamiento anticipado y abstracto. Como sucede con los que desde el primer momento viene planteando la integración del Convenio de Roma, su solución sólo puede perseguirse en el marco de los procedimientos constitucionales atribuidos al conocimiento de este Tribunal, esto es, ponderando para cada concreto derecho y en sus específicas circunstancias las fórmulas de articulación y definición más pertinentes, en diálogo constante con las instancias jurisdiccionales autorizadas, en su caso, para la interpretación auténtica de los convenios internacionales que contienen enunciados de derechos coincidentes con los proclamados por la Constitución española.

Por tanto la duda que aquí puede examinarse es la relativa a la eventual contradicción con la Constitución de una Carta de derechos que, por obra de lo dispuesto en el art. 10.2 CE, debería erigirse, tras su integración en el Ordenamiento español, en pauta para la interpretación de "las normas relativas a los derechos fundamentales y a las libertades que la Constitución reconoce"; ello, claro es, sin perjuicio de su valor en cuanto Derecho de la Unión, integrado en el nuestro ex art. $93 \mathrm{CE}$. No puede ser otro el sentido de la referencia a los artículos II-111 y II-112 del Tratado, que, respectivamente, delimitan el ámbito de aplicación de los derechos de la Carta, por un lado, y los criterios definidores de su interpretación y alcance, por otro. En cuanto a lo primero el Tratado identifica como destinatarios de la Carta a las "instituciones, órganos y organismos de la Unión", así como a los Estados miembros "cuando apliquen el Derecho" de la misma, haciendo expresa salvedad de que con la Carta no se altera, por ampliación, el ámbito competencial de la Unión Europea. Esa reducción del ámbito de aplicabilidad de la Carta y, con ella, de los criterios de interpretación mencionados en el artículo II-112 no podría impedir, 
de prestar el consentimiento en obligarse por el Tratado, que, en tanto que convenio sobre derechos ratificado por España, a través del procedimiento previsto en el art. $93 \mathrm{CE}$, su eficacia interpretativa respecto de los derechos y libertades proclamados por la Constitución tuviera el alcance general previsto en el art. 10.2 CE.

La duda, por tanto, es si la inevitable extensión de los criterios de interpretación de la Carta más allá de los contornos definidos por el artículo II-111 es o no compatible con el régimen de derechos y libertades garantizados por la Constitución. En otras palabras, si los criterios establecidos por el Tratado para los órganos de la Unión y para los Estados miembros cuando apliquen Derecho europeo son o no conciliables con los derechos fundamentales de la Constitución y, en esa medida, pueden también imponerse a los poderes públicos españoles cuando actúen al margen del Derecho de la Unión, es decir, también en circunstancias que no ofrezcan conexión alguna con dicho Ordenamiento. Sin olvidar, por último, que es del todo claro que la aplicación por el juez nacional, como juez europeo, de los derechos fundamentales de la Carta habrá de suponer, casi sin excepción, la simultánea aplicación del correlativo derecho fundamental nacional, hipótesis ante la cual tiene sentido plantearse si la interpretación de los derechos constitucionales a la luz de la Carta (art. 10.2 CE) es a su vez conciliable con la definición que de los mismos se desprende de nuestra jurisprudencia, atenta siempre, como hemos dicho, a los tratados y convenios en la materia.

Es doctrina reiterada de este Tribunal que los tratados y acuerdos internacionales a los que se remite el art. 10.2 de la Constitución "constituyen valiosos criterios hermenéuticos del sentido y alcance de los derechos y libertades que la Constitución reconoce", de suerte que habrán de tomarse en consideración "para corroborar el sentido y alcance del específico derecho fundamental que ... ha reconocido nuestra Constitución" [STC 292/2000, de 30 de noviembre, FJ 8, con referencia, precisamente, a la propia Carta de Niza; también STC 53/2002, de 27 de febrero, FJ 3 b) ]. El valor interpretativo que, con este alcance, tendría la Carta en materia de derechos fundamentales no causaría en nuestro Ordenamiento mayores dificultades que las que ya origina en la actualidad el Convenio de Roma de 1950, sencillamente porque tanto nuestra propia doctrina constitucional (sobre la base del art. 10.2 CE) como el mismo artículo II-112 (como muestran las "explicaciones" que, como vía interpretativa se incorporan al Tratado a través del párrafo 7 del mismo artículo) operan con un juego de referencias al Convenio europeo que terminan por erigir a la jurisprudencia del Tribunal de Estrasburgo en denominador común para el establecimiento de elementos de interpretación com- 
partidos en su contenido mínimo. Más aún cuando el art. I-9.2 determina en términos imperativos que "la Unión se adherirá al Convenio Europeo para la protección de los Derechos Humanos y de las Libertades Fundamentales".

Esa reducción de la complejidad inherente a la concurrencia de criterios para la interpretación no dice nada nuevo a propósito del valor que para la definición de cada derecho haya de tener la jurisprudencia de los Tribunales de la Unión Europea. No supone, en otras palabras, un cambio cualitativo para la relevancia de esa doctrina en la configuración última de los derechos fundamentales por este Tribunal Constitucional. Significa, sencillamente, que el Tratado asume como propia la jurisprudencia de un Tribunal cuya doctrina ya está integrada en nuestro Ordenamiento por la vía del art. 10.2 CE, de manera que no son de advertir nuevas ni mayores dificultades para la articulación ordenada de nuestro sistema de derechos. Y las que resulten, según se ha dicho, sólo podrán aprehenderse y solventarse con ocasión de los procesos constitucionales de que podamos conocer.

Por lo demás no puede dejar de subrayarse que el artículo II-113 del Tratado establece que ninguna de las disposiciones de la Carta "podrá interpretarse como limitativa o lesiva de los derechos humanos y libertades fundamentales reconocidos, en su respectivo ámbito de aplicación, por el Derecho de la Unión, el Derecho internacional y los convenios internacionales de los que son parte la Unión o todos los Estados miembros, y en particular el Convenio Europeo para la Protección de los Derechos Humanos y de las Libertades Fundamentales, así como por las Constituciones de los Estados miembros", con lo que, además de la fundamentación de la Carta de derechos fundamentales en una comunidad de valores con las constituciones de los Estados miembros, claramente se advierte que la Carta se concibe, en todo caso, como una garantía de mínimos, sobre los cuales puede desarrollarse el contenido de cada derecho y libertad hasta alcanzar la densidad de contenido asegurada en cada caso por el Derecho interno.

Ha de concluirse así, en respuesta a la segunda de las preguntas del Gobierno, que no existe contradicción entre la Constitución Española y los arts. II-111 y II-112 del Tratado por el que se establece una Constitución para Europa.

7. En cuanto al tercero de los extremos sobre los que el Gobierno interesa una declaración de este Tribunal; esto es, la suficiencia del art. 93 de la Constitución para la integración del Tratado en el Derecho español, prácticamente ha quedado afirmada dicha suficiencia en los fundamentos jurídicos 
que preceden, por lo que no tiene sentido reiterar aquí lo ya expresado antes, bastando con la mera referencia a lo expuesto.

Otras consideraciones que, siguiendo las indicaciones avanzadas por el Consejo de Estado, plantea el Gobierno sobre la posible conveniencia de introducir modificaciones en la actual redacción del art. 93 CE para aludir expresamente en el mismo al proceso de integración europea e incluso para dar fácil acogida a ulteriores desarrollos de ese proceso, se mueven en el plano de la oportunidad, en el que, obviamente, no podemos pronunciarnos, pues nuestra jurisdicción de su ejercicio se trata también en este procedimiento, como se dijo al principio sólo nos habilita para resolver sobre lo constitucionalmente necesario. Desde esta última perspectiva el art. $93 \mathrm{CE}$ en su texto actual es suficiente para la integración de un Tratado como el que es objeto de nuestro análisis.

8. Finalmente, y en cuanto a la cuarta de las preguntas planteadas por el Gobierno, falta el presupuesto de la misma, que es el de la necesidad de una reforma de la Constitución, la cual no se da en este caso, al no apreciarse contradicción entre los preceptos del Tratado objeto del requerimiento del Gobierno y la Constitución Española, por lo que no tiene sentido pronunciarse sobre dicha pregunta.

En atención a lo expuesto, el Tribunal Constitucional, POR LA AUTORIDAD QUE LE CONFIERE LA CONSTITUCIÓN DE LA NACIÓN ESPAÑOLA,

\section{DECLARA}

1ำ Que no existe contradicción entre la Constitución española y el artículo I-6 del Tratado por el que se establece una Constitución para Europa, firmado en Roma el 29 de octubre de 2004.

2ำ Que no existe contradicción entre la Constitución española y los arts. II-111 y II-112 de dicho Tratado.

$3^{\circ}$ Que el art. 93 de la Constitución española es suficiente para la prestación del consentimiento del Estado al Tratado referido.

$4^{\circ}$ Que no procede hacer declaración alguna en cuanto a la cuarta de las preguntas del Gobierno. 
Publíquese esta Declaración en el "Boletín Oficial del Estado".

Dada en Madrid, a trece de diciembre de dos mil cuatro.

Voto particular que formula el Magistrado don Javier Delgado Barrio respecto de la Declaración correspondiente al Tratado por el que se establece una Constitución para Europa firmado en Roma el 29 de octubre de 2004.

Con el mayor respeto para la opinión de los Magistrados que con su voto han hecho posible la indicada Declaración, he de manifestar mi discrepancia respecto de su fundamentación y conclusiones en la medida en que se refieren al art. I-6 del Tratado.

1. El citado precepto no ofrece dudas en cuanto a la primacía del Derecho comunitario sobre la legalidad infraconstitucional. Así pues, las cuestiones surgen respecto de la primacía del Derecho comunitario sobre la Constitución. La mayoría de mis compañeros ha entendido que esta primacía deriva ya del texto actual del art. $93 \mathrm{CE}$, conclusión que aparece rodeada de una doble línea de razonamiento: por una parte, se entiende que el texto del Tratado hace "difícilmente concebible" que el Derecho comunitario pueda tener un desarrollo "inconciliable" con la Constitución española y, por otra, para el caso que se produjese ese resultado, se indica que este Tribunal resolvería los problemas "a través de los procedimientos constitucionales pertinentes". En definitiva, se piensa que el art. 93 ya en su redacción actual abría el cauce para que el Derecho comunitario desplazase la Constitución, y se añade una cláusula final de garantía por virtud de la cual, en su caso, este Tribunal adoptaría las medidas necesarias "en última instancia" para "la conservación de la soberanía del pueblo español y de la supremacía de la Constitución que éste se ha dado". Así pues, la primacía del Derecho comunitario se reconoce con indudable cautela, pues se articula una a modo de reserva "de la soberanía del pueblo español y de la supremacía de la Constitución”.

En mi opinión, sin embargo, el texto actual del art. 93 CE sólo habilita la primacía del Derecho comunitario sobre la Constitución precisamente en los términos que resultan de dicho precepto: desplazamiento de las normas constitucionales que atribuyen competencias, en lo que ahora importa, normativas, para que pasen a ejercitarlas los órganos señalados en el Derecho de la Unión Europea. En este ejercicio, éstos tienen toda la amplia libertad de configuración normativa que deriva de la Constitución, pero sin margen para apartarse de ésta, salvo en el aspecto subjetivo mencionado. 
Y todavía con carácter previo creo conveniente establecer ya algunas precisiones:

A) Es claro que la primacía o prevalencia del Derecho comunitario y consiguiente desplazamiento de la Constitución sólo tiene virtualidad práctica en la medida en que la norma desplazante —el Derecho comunitario- tenga un contenido diferente a la norma desplazada -la Constitución.

B) El desplazamiento de la Constitución significa que dentro del territorio español, en una materia regulada por aquélla, no se va a aplicar la Constitución. Esto es, claramente, utilizando la terminología de la DTC 1/1992, "disponer" de la Constitución.

En efecto, decíamos entonces que "en virtud del art. 93 las Cortes Generales pueden, en suma, ceder o atribuir el ejercicio de "competencias derivadas de la Constitución", no disponer de la Constitución misma, contrariando o permitiendo contrariar, sus determinaciones". Dado que comparto plenamente la doctrina sentada en dicha Declaración, mi discrepancia de la que ahora formulamos resulta inevitable. En realidad, mi Voto particular no es más que la aplicación de esa doctrina a las preguntas que se nos han formulado.

C) En la misma línea, dejo ya constancia de que no comparto la valoración de nuestra jurisprudencia que se hace en el fundamento jurídico cuarto de la Declaración de la que discrepo. Con cita de varias Sentencias de este Tribunal, se afirma que "nuestra jurisprudencia ha venido reconociendo pacíficamente la primacía del Derecho comunitario sobre el interno", en el ámbito de aquél. Pues bien, creo que es precisamente esa jurisprudencia la que permite descartar que la primacía del Derecho comunitario se proyecte en concreto sobre la Constitución: bastará leer en las citadas SSTC 64/1991, de 22 de marzo, FJ 4 a), y 58/2004, de 19 de abril, FJ 11, que "en conclusión, pues, es claro también que, en la medida en que se impugne en amparo un acto del poder público que, habiendo sido dictado en ejecución del Derecho Comunitario europeo, pudiera lesionar un derecho fundamental, el conocimiento de tal pretensión corresponde a esta jurisdicción constitucional con independencia de si aquel acto es o no regular desde la estricta perspectiva del ordenamiento comunitario europeo y sin perjuicio del valor que éste tenga a los efectos de lo dispuesto en el art. 10.2 CE”. Es decir, el acto podrá ser válido con arreglo al Derecho comunitario, pero si vulnera un derecho fundamental reconocido en la Constitución, habrá de ser anulado. No veo aquí, en modo alguno, primacía del Derecho comunitario con desplazamiento de la Constitución. 
2. En definitiva, la cuestión planteada es la de si el art. 93 CE, en su actual redacción, es suficiente para habilitar ese desplazamiento de nuestra Constitución, habida cuenta de su naturaleza de norma suprema, afirmada "de modo inequívoco y general en su art. 9‥1" (STC 80/1982, de 20 de diciembre, FJ 1).

Examinaré separadamente ambos preceptos, para llegar a la conclusión derivada de su conexión:

A) El art. 9.1 CE ("Los ciudadanos y los poderes públicos están sujetos a la Constitución y al resto del ordenamiento jurídico") cumple una función capital en nuestra Constitución, dentro de su Título Preliminar: no sólo refleja la imperatividad, la fuerza obligatoria del Derecho - lo que es una obviedad, que opera sobre los ciudadanos y también sobre los poderes públicos —nota instrumental del Estado de Derecho ya proclamado en el art. 1.1- sino que, y esto es lo relevante, expresa la naturaleza normativa de la Constitución que se integra en el ordenamiento jurídico, y que además es, precisamente, la norma suprema.

Ciertamente, son numerosos los preceptos de la Constitución en los que aparecen estas notas —naturaleza normativa, carácter supremo-, pero todos ellos vienen a ser manifestación, consecuencia de aquéllas; es justamente el art. 9.1 CE el que cumple el cometido de hacer expresa directamente esa condición de la Constitución, que no podía faltar dentro de su Título Preliminar, que es la quintaesencia de nuestra Norma Fundamental, en cuanto "que contiene los principios inspiradores de la misma " (STC 101/1983, de 18 de noviembre, FJ 3).

B) El art. $93 \mathrm{CE}$ abre la posibilidad de que mediante ley orgánica se pueda autorizar la celebración de tratados por los que se atribuya a una organización o institución internacional el ejercicio de competencias derivadas de la Constitución.

La literalidad de la norma habilita para que se modifique subjetivamente el ejercicio de alguna competencia prevista en la Constitución, pero tal modificación es, en esa literalidad, estrictamente subjetiva: será un sujeto distinto al previsto en la Constitución el que pueda ejercer la competencia para elaborar las normas que las exigencias de la Unión Europea reclamen, con toda la amplísima libertad de configuración que abre la propia Constitución, pero tal competencia, en su contenido objetivo, estará sujeta a las exigencias "derivadas de la Constitución”. La primacía del Derecho comunitario en los actuales 
términos del art. $93 \mathrm{CE}$ significa que las atribuciones de competencias hechas en la Constitución quedan desplazadas por las hechas en el Tratado, de suerte que serán ejercidas por otros sujetos, pero no hay más desplazamiento de la Constitución que el que acaba de indicarse.

Así lo señalaba expresamente la DTC 1/1992: "el art. 93 CE no puede ser empleado como instrumento para contrariar o rectificar mandatos o prohibiciones contenidas en la Norma Fundamental ... pues el tenor literal y el sentido mismo del art. 95.1, aplicable a todo tipo de tratados, excluyen con claridad el que mediante cualquiera de ellos puedan llegar a ser contradichas o excepcionadas las reglas constitucionales que limitan, justamente, el ejercicio de todas las competencias que la Constitución confiere, algunas de las cuales pueden ser cedidas, quoad exercitium, en virtud de lo dispuesto en su art. 93. Los poderes públicos españoles no están menos sujetos a la Constitución cuando actúan en las relaciones internacionales o supranacionales que al ejercer ad intra sus atribuciones, y no otra cosa ha querido preservar el art. 95, precepto cuya función de garantía no debe resultar contrariada o disminuida por lo prevenido en el art. 93 de la misma Norma Fundamental".

Es claro, pues, que la literalidad que hoy presenta el art. 93 CE no permite que el ejercicio de las competencias a que se refiere pueda servir para apartarse de la Constitución, o, lo que es lo mismo, aquel precepto no habilita el desplazamiento de la Constitución por el Derecho comunitario, salvo en lo relativo al sujeto al que se atribuye el ejercicio de la competencia.

C) Sobre esta base, ¿puede entenderse el art. 93 CE, en su actual texto, habilitación suficiente para que a través de un tratado el Derecho comunitario desplace no sólo la normativa infraconstitucional - lo que no ofrece duda- sino también la propia Constitución, norma jurídica suprema, tal como declara "de modo inequívoco" el art. 9.1 CE (STC 80/1982, de 20 de diciembre, FJ1)?

La mayoría de mis compañeros entiende que sí, basándose en que el art. $93 \mathrm{CE}$ era precisamente el medio constitucional para nuestra integración en la hoy Unión Europea, de suerte que, sobre su base, con la Ley Orgánica 10/1985 venían a acogerse los principios propios del Derecho comunitario, entre los que figura el de primacía.

De lo que es, sin duda, una base cierta —el art. 93 CE cumplía la función de establecer el cauce para la integración de España en las Comunidades Europeas- se extrae una conclusión que no lo es tanto: ¿realmente el constitu- 
yente quiso aceptar la primacía del Derecho comunitario no sólo sobre la legalidad infraconstitucional, sino también sobre la Constitución misma? y, ya en otro sentido, ¿tal designio ha dejado alguna huella en el texto del art. 93 que permita pensar que, objetivamente, ese es el resultado plasmado en la norma?

En mi opinión las respuesta a ambas preguntas ha de ser negativa.

a) Ante todo, ha de atenderse al propósito del constituyente precisamente en 1978, momento de la redacción del precepto, y no a la Ley Orgánica 10/1985, nacida del art. $93 \mathrm{CE}$, y que no es dato para la interpretación de la Constitución -ésta no se interpreta por aquélla, sino aquélla por ésta-. Ciertamente, en 1978, la jurisprudencia del Tribunal de Justicia de las Comunidades Europeas había ya establecido el principio de la primacía del Derecho comunitario sobre el Derecho interno, primacía que la Sentencia Internationale Handelsgessellschaft, de 17 de diciembre de 1970, había concretado en estos términos: "la invocación de atentados sea a los derechos fundamentales tal como son formulados por la Constitución de un Estado miembro, sea a los principios de una estructura constitucional nacional no puede afectar a la validez de un acto de la Comunidad o a su efecto sobre el territorio de este Estado". Y no creo que pueda pensarse que fuera designio del constituyente admitir la primacía del Derecho comunitario en esos términos, cuando eran varios los Tribunales Constitucionales que oponían serias reservas a una primacía así concebida. Más aún, nuestro Tribunal Constitucional, intérprete supremo de la Constitución, este mismo año 2004, rechazaba esa primacía del Derecho comunitario sobre la Constitución. Así la STC 58/2004, de 19 de abril, FJ 11, reiterando la doctrina de la STC 64/1991, de 22 de marzo, FJ 4, a), declaraba: "en conclusión, pues, es claro también que, en la medida en que se impugne en amparo un acto del poder público que, habiendo sido dictado en ejecución del Derecho Comunitario europeo, pudiera lesionar un derecho fundamental, el conocimiento de tal pretensión corresponde a esta jurisdicción constitucional con independencia de si aquel acto es o no regular desde la estricta perspectiva del ordenamiento comunitario europeo y sin perjuicio del valor que éste tenga a los efectos de lo dispuesto en el art. 10.2 CE"

b) Pero no se trata sólo de que esa aceptación de la primacía del Derecho comunitario sobre la Constitución por nuestro constituyente no me parezca concluyente, sino que, además, y esto es lo relevante, no aparece reflejada de ninguna manera en el art. $93 \mathrm{CE}$, que en último término establece algo de un contenido perfectamente concretado y definido. 
Nuestro Tribunal Constitucional ha puesto de relieve que "el respeto de la Constitución que el art. 9 de la misma impone a todos los Poderes Públicos hace necesario que una interpretación que conduzca a un resultado distinto de la literalidad del texto sólo sea pensable cuando existe ambigüedad o cuando la ambigüedad puede derivar de conexión o coherencia sistemática entre preceptos constitucionales" (SSTC 72/1984, de 14 de junio, FJ 6, y 215/2000, de 18 de septiembre, FJ 6). Y también reiteradamente ha declarado que "la importancia de la interpretación sistemática, consecuencia del principio de unidad de la Constitución — STC 179/1994, de 16 de junio, FJ 5-, pues ésta es un todo en el que cada precepto encuentra su sentido pleno valorándolo en relación con los demás, es decir, de acuerdo con una interpretación sistemática (STC 5/1983, de 4 de febrero, FJ 3)" (STC 16/2003, de 30 de enero, FJ 5).

Y aquí, como he señalado, la actual literalidad del art. 93 no permite que el ejercicio de las competencias a las que se refiere dicho precepto pueda servir para apartarse de la Constitución. No hay ambigüedad en el propio precepto, ni tampoco tal ambigüedad puede derivar de la conexión con el art. 9.1 CE que proclama la supremacía de la Constitución. Dicho con la terminología de la Sentencia citada, no resulta "pensable" una interpretación del art. 93 CE que se aleje del que hoy es su texto literal para habilitar un desplazamiento de la Constitución en algo más que en la pura atribución de competencias. Como ya he indicado, la primacía del Derecho comunitario sobre la Constitución, es decir, el desplazamiento de ésta por aquél, adquiere virtualidad práctica cuando la norma desplazante tiene un contenido distinto al de la norma desplazada y, así las cosas, el efecto de ese desplazamiento es que la Constitución Española, dentro del territorio español, en una materia regulada por ella, deja de ser aplicada para ser sustituida por otra de contenido diferente. Ciertamente, el desplazamiento no implica una derogación o reforma de la Constitución, pero el resultado práctico viene a ser, al menos temporalmente, coincidente: inaplicación de la Constitución y aplicación de un precepto de sentido normativo diferente. Con ello se habría producido una "disposición" de la Constitución que excede ampliamente de lo actualmente permitido por el art. $93 \mathrm{CE}$ que, como he subrayado, apodera para una modificación puramente subjetiva del régimen constitucional de las competencias, pero en modo alguno permite que el ejercicio de éstas se desarrolle fuera de la sujeción a la Constitución. Así, la DTC 1/1992 señalaba terminantemente que dicho precepto no habilita para "disponer de la Constitución misma, contrariando o permitiendo contrariar sus determinaciones".

c) Y es que, en realidad, concluyendo, el desplazamiento de la Constitución por el Derecho comunitario afecta tan profundamente a la esencia mis- 
ma de la Constitución como norma jurídica suprema que llega a integrar una limitación de la soberanía del pueblo español (art. 1.2 CE), que sólo puede producirse como efecto de un decisión del constituyente que ha de resultar "de modo inequívoco" de la propia Constitución. Y no acierto a ver en la actual redacción del art. 93 CE esa decisión inequívoca de habilitar el desplazamiento de la Constitución por el Tratado y el Derecho derivado más allá del aspecto subjetivo ya indicado.

3. De lo expuesto deriva que nuestras respuestas a la primera y tercera de las preguntas que se nos han formulado hubieran debido ser que existe contradicción entre la Constitución española y el art. I-6 del Tratado por el que se establece una Constitución para Europa y que el art. 93 CE no es suficiente para la prestación del consentimiento del Estado a dicho Tratado. En cuanto a la cuarta pregunta, dado que no se ha producido deliberación sobre este punto, no creo procedente exponer mi reflexión al respecto.

Y para adecuada constancia de mi opinión discrepante, suscribo el presente Voto particular, en Madrid, a trece de diciembre de dos mil cuatro.

Voto particular que formula el Magistrado don Roberto García-Calvo y Montiel respecto a la Declaración emitida por este Tribunal Constitucional el 13 de diciembre de 2004 bajo el número 6603-2004.

1.- Con el máximo respeto para el criterio y decisión adoptados por la mayoría de mis compañeros del Tribunal emito este Voto particular con el fin de motivar mi discrepancia con la Declaración y ello, tanto porque disiento de parte de su estructura analítica como de varios de los apartados dispositivos que le sirven de colofón.

Lo primero en cuanto que estimo que si la formulación de las preguntas dirigidas a este Tribunal por el Gobierno se hizo siguiendo un orden lógico y de prioridades, a este debemos ajustar nuestra respuesta, sin que, para mi, aparezca justificada su alteración.

Lo segundo, porque por más que trate de justificarse conclusión tan terminante como la que alcanza la mayoría de los componentes de este Tribunal y se plasma en el primer y tercer apartado de la Declaración afirmando que "no existe contradicción entre la Constitución española y los artículos I-6 del Tratado por el que se establece una Constitución para Europa firmado en Roma el 29 de octubre de 2004" y "que el art. 93 CE es base suficiente para la 
prestación de consentimiento del Estado al Tratado referido", con todo respeto afirmo que no me resultan ni válidos ni suficientes - por lo forzado de su instrumentación y por la debilidad de su contenido- los argumentos que se plasman en la referida declaración jurisdiccional para mantener tal determinación conclusiva.

2.- Al desarrollo de mi posición dedico las siguientes líneas, no sin antes señalar que parto para tal misión —asumiendo la reflexión finalista que se contiene en el fundamento jurídico primero de dicho pronunciamiento- sobre la función específica que el legislador encomienda a este Tribunal en el art. 95-2 de la Constitución (regulada en su cauce procesal por el art. 78 LOTC) y que no es otra - tomo aquí literalmente las palabras de la Declaración con la que muestro en este Voto mi disentimiento- que "asegurar la supremacía de la Constitución sin perjuicio alguno para los compromisos internacionales que España pueda contraer, procurando evitar que la posible contradicción entre una y otros haya de resolverse una vez integradas en el ordenamiento las normas pactadas".

Por otra parte, debo añadir que estoy de acuerdo con el discurrir argumental que - por referencia a nuestra Declaración de 1 de julio de 1992— se desarrolla en el referido fundamento jurídico primero, aún cuando no comparto el contenido de la explicitación que se ofrece en el fundamento jurídico segundo para justificar la diferenciación de los parámetros que enmarcan aquélla Declaración y las que presiden la actual decisión del Tribunal cuando se afirma: "lo que dijimos en la DTC 1/1992 se situaba en unas coordenadas precisas, consistentes entonces en la existencia de una contradicción entre el art. 8b del Tratado de Maastrich con el texto de la Constitución (art. 13.2), siendo estas coordenadas en las que debe entenderse el alcance de algunos de los contenidos de dicha Declaración a la hora de emitir la actual, que opera en el marco de unas coordenadas diferentes, en las que tal contradicción con el texto no se da" ( $s i c)$, dado que tal distinción está exclusivamente basada en una pura delimitación formal operativa que en nada puede afectar a la esencialidad de la cuestión ni a la función que a este órgano constitucional le corresponde según los propios términos que anteceden al referido primer inciso expositivo, en tanto que la justificación ofrecida para dicha consideración es del siguiente tenor: "Tal dimensión fue la única considerada en la citada Declaración tan solo a fin de determinar si el art. 93 CE era mecanismo adecuado para excepcionar el límite que el art. 13.2 CE establecía a la extensión a los extranjeros por tratado o por ley del derecho de sufragio pasivo en las elecciones municipales, concluyéndose ante contradicciones atinentes al texto de una norma constitucional sustantiva que dicho precepto no incorpora 
un cauce revisorio equiparable a los procedimientos de reforma constitucional regulados en el título X CE. Pero si es el cauce previsto por la Constitución para transferir o atribuir a organizaciones o instituciones internacionales el ejercicio de competencias derivadas de la misma, modulándose así, por tanto, como reconocimos en aquella Declaración, el ámbito de aplicación y ordenación del ejercicio de las competencias cedidas (FJ 2)" (sic).

Si allí también se decía que no era el art. 93 instrumento para contrariar o rectificar los mandatos constitucionales, ni para disponer de la Constitución misma, ni cauce legítimo para su reforma implícita o tácita, no encuentro razón convincente para coincidir con el tratamiento jurisdiccional mayoritario que resuelve algunas de las cuestiones sometidas a nuestra consideración pues, únicamente otorgo a las referidas afirmaciones el valor de un recurso dialéctico a través del cual se reconducen los argumentos que las subsiguen en los fundamentos posteriores, estableciendo una premisa de la Declaración muy reveladora - por la dosis de anticipación que contiene- de su parte dispositiva.

3.- También he de discrepar de las que -en el propio fundamento jurídico segundo- se anuncian como "algunas consideraciones previas sobre el alcance y contenido del art. $93 \mathrm{CE}$ ", no sólo porque de tal acotamiento paradójicamente habla por si solo su extenso tratamiento (folios 13, 14 y 15 de la resolución), sino porque con la simple invocación de dicha propuesta expositiva aparece justificada implícitamente una alteración del orden de respuesta del planteamiento del Gobierno en lo que se refiere al citado art. $93 \mathrm{CE}$ que me resulta inaceptable porque en sí misma constituye una real mutación, (tal como lo demuestra tanto el contenido del fundamento jurídico noveno como la numeración ordenada de la parte dispositiva de la Declaración), salvo que se asuma sin reservas el lenguaje eufemístico que impregna muchos pasajes de la resolución y con el que, según mi criterio, se trata de propiciar el sentido de un fallo que ya, en virtud de esas primeras objeciones $y$, jurisdiccionalmente hablando, rechazo por heterodoxo.

4.- Desde esa perspectiva discrepante con el enfoque precitado, he de desgranar ahora las razones que me separan de quienes - la mayoría de los componentes del Tribunal- afirman contundentemente ya en el fundamento jurídico cuarto de la Declaración que "no existe la contradicción" a que se refiere el apartado primero del requerimiento formalizado por el Gobierno a este Tribunal acerca de la existencia o no de aquélla entre la Constitución española y el art. I-6 del Tratado por el que se establece una Constitución para Europa, pues "con base a lo dispuesto en el art. $93 \mathrm{CE}$ y dadas las concretas 
previsiones del Tratado ya señaladas en el fundamento jurídico precedente no es posible apreciar contradicción alguna entre el art. I-6 del Tratado y el art. 9.1 CE, no dándose en definitiva, el supuesto normativo del art. 95.1 CE”.

En este punto, hago míos los argumentos de un ilustre miembro de este Tribunal, experto constitucionalista, que antes de ejercer la función jurisdiccional, ha publicado textualmente:

"La afirmación explícita por la Constitución Europea de su primacía sobre los ordenamientos interno, incluida la propia Constitución, supone una auténtica antinomia con el art. 9.1 de la Constitución nacional, insalvable por vía imperativa, y que exige reforma constitucional según la doctrina del Tribunal Constitucional mantenida en la Declaración sobre el Tratado de la Unión Europea de 1 de julio de 1992-" (sic).

"En el caso del Tratado Constitucional, la antinomia se produce con un precepto especialmente protegido por lo que cualquier reforma que se haga, se ubique formalmente en un lugar u otro, parece que 'afecta' al art. 9.1, lo que conduce a que la opción debería ser la reforma agravada.

Ciertamente, esta solución plantea los problemas técnicos y políticos que suscita el procedimiento de reforma agravada previsto en la Constitución, extraordinariamente complejo y con el coste menor si se decide bien el momento. Pero, a su vez, la supremacía de la Constitución, tal y como se ha concebido en nuestra Norma Fundamental y tal y como ha sido interpretada por el Tribunal Constitucional, parece imponer esta solución. Y no debe olvidarse que sería muy peligroso desde el punto de vista político proceder de manera constitucionalmente incorrecta a la hora de dar un pasa tan importante como es el de la participación española en este nuevo reto de la integración europea; por mucha legitimidad que se pudiera obtener en un referéndum consultivo, sería una legitimidad viciada desde la perspectiva constitucional. Mal estaría arrancar de forma inconstitucionalmente correcta en este nuevo camino de 'constitucionalización' de Europa sólo porque nuestro constituyente fue excesivamente rígido a la hora de regular la reforma constitucional (recuérdese que como forma de valorara la propia Constitución) o porque desde los poderes públicos se dejen llevar de esa especie de miedo atávico que la reforma constitucional ha inspirado y que mal casa con la idea misma de Constitución. Ésta no hay que cambiarla si no es necesario, pero tiene que cambiarse cuando ella misma lo exige o cuando la realidad política lo aconseja, y ambas cosas sucederán ante la ratificación, nada más y nada menos, de la primera 'Constitución Europea'”. (sic). 
5.- Para alcanzar la conclusión de la que discrepo, he de acudir de nuevo al texto mayoritariamente aprobado, el cual, después de referirse a la supremacía que se proclama en el Tratado por el que se establece una Constitución para Europa y a las garantías que aseguran los valores comunes de las Constituciones de los Estados integrados en la Unión y de sus tradiciones constitucionales a través de los principios de atribución, subsidiariedad y proporcionalidad (fundamento jurídico 3), hace referencia a una cláusula de cierre argumental con la que se despejarían todas las dudas planteadas por el Gobierno de la Nación a la vista de la recomendación formulada por el Consejo de Estado, órgano que, después de analizar la proclamación explícita y formal en el art. I-6 de la Constitución Europea del principio de primacía del Derecho de la Unión, cuestiona el posible conflicto entre este precepto y nuestra Constitución, entendida ésta como norma suprema de nuestro ordenamiento jurídico.

Dicha cláusula -contenida en el inciso final del fundamento jurídico $4^{\circ}-$ literalmente dice:

"En el caso difícilmente concebible de que en la ulterior dinámica del derecho de la Unión Europea llegase a resultar inconciliable este derecho con la Constitución Española, sin que los hipotéticos excesos del Derecho europeo respecto de la propia Constitución Europea fueran remediados por los ordinarios cauces previstos en ésta, en última instancia la conservación de la soberanía del pueblo español y de la supremacía de la Constitución que éste se ha dado podrían llevar a este Tribunal a replantearse los problemas que desde la perspectiva actual se consideran inexistentes; ello aparte de que la salvaguarda de la referida soberanía siempre resulta a la postre asegurada por el art. I60 del Tratado, verdadero contrapunto de su Art. I-6, y que permite definir en su verdadera dimensión la primacía proclamada en este último, incapaz de sobreponerse al ejercicio de una renuncia, que queda reservada a la voluntad soberana, suprema, de los Estados miembros" (sic)

Pues bien, y en primer lugar, tan contundente y actualizado descarte de la problemática referida a la "conservación de la soberanía del pueblo español y de la supremacía de la Constitución", no sólo no me resulta de recibo una vez que - tomando literalmente palabras del dictamen del Consejo de Estado- "el Tratado eleva a norma de la Constitución para la Europa la primacía del Derecho comunitario. Dicho principio, que se ha calificado como una 'exigencia existencial' de tal Derecho, como se sabe, es fruto de la construcción jurisprudencial del Tribunal de Justicia de las Comunidades Europeas a partir de la Sentencia de 15 de julio de 1964 (Costa c. ENEL) y desarrollado en pronunciamientos posteriores, así las SSTJCE de 14 de diciembre de 1971 (Poli- 
to), 13 de julio de 1972 (Comisión c. Italia), 9 de marzo de 1978 (Simenthal), entre otras muchas, y significa que cualquier norma del Derecho comunitario, no sólo del primario sino del derivado, prevalece sobre las de Derecho interno cualquiera que sea el rango de éstas incluido el constitucional. Opera, pues, contra cualquier fuente ya sea anterior o posterior al Derecho comunitario y respecto tanto de los órganos jurisdiccionales como del resto de los órganos del Estado" ( $s i c$ ), sino que, desde una perspectiva fundada en la preservación de los intereses reales de la nación española y no en la de la consolidación de postulados teóricos, no me consuela contemplar -por irreal y utópicala hipótesis de nuestra renuncia a la integración política y, esencialmente, económica en la Unión Europea.

De ahí mi esfuerzo -que no por baldío he de dejar de expresar-para tratar de prevenir una alternativa de aislamiento en el concierto comunitario cuando, ante la duda de contradicción ya identificada, se nos ofrece la oportunidad de operar sobre bases de consenso o asentimiento popular que aseguren la adopción de una decisión que ha sido trasladada a este Tribunal, pues, tanto me intranquiliza la de tener que renunciar en un futuro no lejano a nuestra integración en la Unión Europea para preservar la conservación de la soberanía del pueblo español y la supremacía de nuestra Carta Magna, como la alternativa de permanecer integrado en un Comunidad de Estados regida por una norma suprema sobre la que yo, superando las dudas manifestadas por el Gobierno y el Consejo de Estado acerca de su contradicción con el título preliminar (específicamente con al art. 9.1) de nuestra Constitución, me inclino hasta la certeza de tal antinomia.

6.- Por todo lo que antecede, postulo la puesta en marcha de las prevenciones normativas que establece el art. 168 del texto constitucional, pues la distinción entre primacía y supremacía para justificar la compatibilidad de la Constitución española con regímenes de aplicación que den preferencia a normas internacionales siempre que éstas se hayan incorporado al ordenamiento nacional en la forma constitucionalmente prescrita y pretendan esta aplicabilidad preferente en virtud del régimen propio asumido por la Constitución -con lo que, en definitiva, esa aplicabilidad preferente es reconducible a una concreta previsión constitucional, que de poder ser valorable como limitación de la Constitución, sería en todo caso autolimitaciónqueda reducida a un puro recurso dialéctico, una vez que la posibilidad de recuperar la supremacía constitucional se configura por el momento como un planteamiento teórico -no empírico- que por sus imprevisibles consecuencias y, desde una perspectiva realista, yo no puedo en este momento asumir. 
7.- Todas las cautelas que destila el texto jurisdiccional mayoritariamente votado y a las que ha hecho precedente referencia, evidencian-según mi modesta opinión- los riesgos de una aceptación integral y sin reservas de la propuesta constitucional comunitaria, la cual, de seguro y, cuando menos, propiciará constantes pronunciamientos de este Tribunal ante desarrollos normativos de la Carta Magna Europea. Curémonos en salud antes de abrir la cancela de las más que seguras decisiones terapéuticas de corrección interpretativa, aplicativa o de preservación de nuestra integridad constitucional propiciadas por una conclusión como la que aporta la declaración adoptada por este Tribunal.

Considero que las meritadas prevenciones no serían exigibles o adquirirían per se necesarias dosis de legitimación popular si, en lugar de un acuerdo jurisdiccional homologante de una contradicción que considero esencial-tal es la afectación del art. 9.1 CE-, se pusieran en marcha las prevenciones establecidas en el precitado art. 168 CE.

8- En definitiva, creo que estamos ante un real traspaso de soberanía con hipotética cláusula de reversión. Por ello y, aún cuando sólo se asuma esa premisa desde posiciones dubitativas, la trascendencia de la cuestión exige, a mi modesto entender, la activación del mecanismo reforzado de homologación del referido art. 168 a fin de preservar o, en su caso, rectificar, el contenido esencial que el constituyente quiso y delimitó para, entre otros, el título preliminar de nuestra Carta Magna.

En su consecuencia, no creo que pueda suscribirse sin duda alguna y con la solemnidad que implica una Declaración de esta naturaleza la afirmación de que no hay contradicción entre uno y otro texto, cuando voz tan autorizada como la del actual Presidente del Consejo de Estado ha afirmado públicamente a mediados del pasado año lo que a continuación transcribo en su literalidad:

"La convocatoria de otro referéndum, no consultivo, sino decisorio, es indispensable para hacer compatible la "Constitución" europea con la española y, en consecuencia, también para legitimar aquélla sin deslegitimar ésta, la única que realmente tenemos.

El argumento que lleva a esta conclusión es muy simple, perfectamente lineal y a mi juicio incontestable. El artículo I-10 de esta nueva 'Constitución' en forma de Tratado Internacional, y que sólo como Tratado puede ser modificada o derogada, dispone que "la Constitución, y las normas dictadas por 
las instituciones europeas en ejercicio de sus competencias, prevalecerán sobre el derecho de los Estados miembros." Esta cláusula de supremacía, que recuerda la del art. VII de la Constitución norteamericana y que obliga a dejar de lado, no sólo las leyes españolas, sino incluso la propia Constitución, cuando aquéllas o ésta estén en contradicción con el Derecho europeo, incluidos, por supuesto, los reglamentos y las directivas, decisiones y resoluciones, es incompatible con el principio de supremacía de nuestra propia Constitución, inherente a la idea misma de Constitución como norma y explícito además en el art., 9-1 y otros preceptos del propio texto constitucional.

La afirmación de la supremacía del derecho europeo sobre los derechos nacionales no es en rigor una novedad, ni un invento de la Convención. El Tribunal de Justicia, que ha hecho de ella el fundamento de toda su jurisprudencia, viene reiterándola desde comienzo de los años sesenta y es ese principio el que ha llevado a sostener que Europa (las Comunidades primero, y la Unión Europea, después) tenía ya su propia Constitución antes de que la Convención iniciara sus trabajos. El origen puramente jurisprudencial del principio y la naturaleza simplemente 'material' de la Constitución que sobre él se asentaba, no ocultaban la oposición lógica entre las dos pretensiones de supremacía recíprocamente excluyentes, la de la 'Constitución' europea, de una parte, y las distintas Constituciones nacionales, de la otra, pero han permitido abordarla como si fuera un problema de relación entre tribunales, e ir sorteándola con construcciones más o menos afortunadas, como ha hecho el Tribunal Constitucional alemán, o más bien ignorándola, como ha tendido a hacer el nuestro. El Tratado de Maastricht, con el que se creó la Unión Europea, no incorporó ese principio, que sin embargo daba por supuesto. A pesar de ese silencio, algunos Estados que toman en serio sus propias Constituciones, como Alemania y Francia, se sintieron ya obligados a reformarlas para salvar la contradicción implícita, que era la importante, no la explícita y trivial que dio lugar a la reforma de la nuestra. Por eso ahora quizás esos Estados no se sientan obligados a reformarlas otra vez para ratificar el nuevo Tratado, aunque esa actitud sólo me parece fundada en el caso de Alemania, que en 1992 abrió también la posibilidad de que los sucesivos Tratados europeos sirvieran de vía para la reforma de la Constitución. En el caso de España, la consagración ya perfectamente explícita del principio de supremacía como norma 'constitucional', hace imposible la ratificación del nuevo Tratado que instituye la 'Constitución' de la Unión sin reformar previamente la nuestra, cuyo artículo 93 autoriza a las Cortes para atribuir a una 'organización o institución internacional el ejercicio de competencias derivadas de la Constitución', pero no para poner en manos de esas organizaciones e instituciones la decisión sobre su propio contenido. 
Ese poder sobre la propia Constitución es el efecto real de la cláusula de supremacía. Al aceptarla, estamos transfiriendo a las instituciones europeas la potestad de reformar nuestra Constitución, siempre que, en el ejercicio de sus competencias propias, estimen necesario hacerlo. El hecho de que las reformas así producidas sean tácitas, no expresas, no cambia su naturaleza, ni permite ignorar que lo que se transfiere no es el ejercicio de algunas competencias concretas de órganos del Estado, sino el del poder soberano del pueblo español para establecer su propia Constitución. La incompatibilidad manifiesta entre el Tratado propuesto por la Convención y la Constitución española hace imposible por eso ratificar aquél sin reformar antes ésta, que es lo que en ella se prevé para casos como éste. Si la ratificación se hace sin esa reforma, los jueces españoles seguirán encontrándose ante un dilema sin solución cuando se encuentren en la necesidad de aplicar normas europeas contrarias a nuestra Constitución, y nuestro Tribunal Constitucional podrá seguir desentendiéndose, como hasta ahora, de la obligación que nuestros jueces tienen de aplicar el derecho europeo cuando las circunstancias del caso lo exijan. Sobre todo, y eso es con mucho lo peor, para hacer posible una 'Constitución' europea, habremos reducido definitivamente la nuestra a puro papel mojado; a un guiñapo que se puede agitar siempre que conviene, pero que no hay que tomar demasiado en serio.

Aunque esta reforma imprescindible puede circunscribirse quizás al art. 93 de la Constitución, es evidente que su contenido afecta a preceptos capitales del Título Preliminar y que, en consecuencia, ha de hacerse siguiendo el engorroso procedimiento previsto para estos supuestos, que implica, entre otras cosas, la aprobación de la reforma por dos legislaturas sucesivas y, tras ello, la celebración de un referéndum." (sic).

Por todo ello y, entendiendo que mi coincidencia con los posicionamientos doctrinales reproducidos textualmente -de ahí sus citas de autoridad- sirven para reforzar definitivamente la discrepancia contenida en este Voto particular, emito el mismo con mi anticipado respeto al resto de los componentes del Tribunal de los que disiento y con el concreto alcance que su propio contenido le otorga en relación con los reseñados fundamentos jurídicos y con los tres primeros apartados de la parte dispositiva de la Declaración.

En Madrid, a trece de diciembre de dos mil cuatro.

Voto particular que formula el Magistrado don Ramón Rodríguez Arribas en el requerimiento (asunto núm. 6603-2004) formulado por el Abogado del 
Estado, en nombre y representación del Gobierno de la Nación, acerca de la existencia o inexistencia de contradicción entre la Constitución española y los artículos I-6, II -111 y II-112 del Tratado por el que se establece una Constitución para Europa, firmado en Roma el 29 de octubre de 2004.

En el ejercicio de la facultad que nos confiere el art. 90.2 LOTC y con pleno respeto a la opinión de la mayoría, expreso mi discrepancia con la Declaración que al respecto formula el Pleno de este Tribunal, que fundo en las siguientes consideraciones:

1.- No puedo compartir la principal conclusión a la que se llega, es decir, que no existe contradicción entre el Tratado por el que se establece una Constitución para Europa y la Constitución española.

En efecto, el art. 9.1 CE dice lo siguiente:

"Los ciudadanos y los poderes públicos están sujetos a la Constitución y al resto del ordenamiento jurídico".

Por su parte el art. I-6 de la que se proyecta como Constitución para Europa y sobre la que versa expresamente la primera pregunta que se ha formulado por el Gobierno de la Nación, dice:

"La Constitución y el Derecho adoptado por las instituciones de la Unión en el ejercicio de las competencias que se le atribuyen a esta primarán sobre el Derecho de los Estados miembros".

La patente antinomia entre la literalidad de ambos preceptos no es posible anularla, a mi juicio, con ninguna interpretación que tienda a hacerlos compatibles apartándose del tenor de sus respectivos textos.

El art. 9.1 CE ha sido reconocido por la doctrina, la jurisprudencia y la práctica forense, como la expresión del principio de seguridad jurídica, que se asienta en el respeto a la jerarquía normativa, de manera que resulta fundamental la ausencia de dudas razonables sobre que normas tienen prevalencia sobre otras y sobre todas ha de estar la Constitución de España, como ha declarado este Tribunal.

Pues bien, esa prevalencia ( que es el concepto y la palabra mas comúnmente usados) va a quedar desplazada -aunque solo sea en las cuestiones que afecten al ejercicio de las competencias atribuidas a la Unión Europea- por la 
Constitución y el Derecho europeos, quebrando la que, de otro modo, seria absoluta e indiscutible prevalencia de la Constitución Española sobre cualquier otra norma jurídica. Situación a la que tal vez sea inevitable llegar para alcanzar plenamente la deseada unión de Europa, pero no debe discurrir por más camino que el de las propias normas jurídicas, incluidas las de nuestra Constitución.

Dejando las cosas así, es decir, declarando que no existe contradicción, los ciudadanos y los poderes públicos españoles, cuando se encuentren con una norma del derecho europeo que contradiga preceptos de nuestra Constitución, se verán en la disyuntiva de faltar al mandato constitucional interno, inaplicar la norma europea o bien -en el caso de nuestro tribunales ordinarios- plantear la cuestión de inconstitucionalidad ante nosotros o la cuestión prejudicial ante el Tribunal de Justicia de la Unión Europea, situación que, cualquiera que sea la probabilidad y frecuencia con que pudiera producirse, constituye un grave quebranto de la seguridad jurídica, un peligro que no puede negarse, que no es razonable correr, ni conjurar recurriendo a la posible intervención posterior del Tribunal Constitucional o a la impensable posibilidad de retirarse de la Unión Europea, conforme prevé el art. I-60 de la que pretende ser su Constitución. Mucho mas razonable y prudente y sobre todo necesaria, es la opción de reconocer la contradicción y adoptar ya la reforma constitucional para regularla o, como mínimo, tomar en la interpretación del Tratado y del art. $93 \mathrm{CE}$ precauciones que no se han incluido en la declaración, al menos de la manera expresa y contundente que serían, a mi juicio, necesarias.

2.- Cierto es que desde el ingreso de España en las, entonces llamadas, Comunidades Europeas, el 1 de enero de 1986, se fue abriendo paso en nuestro sistema jurídico la aplicación de los Reglamentos y Directivas comunitarias, incluso -estas últimas- sin necesidad de transposición o antes de que se produjera, llegándose a otorgar, con naturalidad, la primacía a las normas europeas, con desplazamiento de nuestro derecho interno, lo que ha venido siendo particularmente intenso en materia económica y tributaria; sin embargo, no puede olvidarse que lo que nunca se llegó a plantear fue la supeditación de la aplicación de nuestra Constitución al derecho europeo, al contrario, se daba por supuesta la primacía de aquélla, aceptándose únicamente que el desplazamiento del derecho propio afectaba solo a normas infraconstitucionales (SSTC 28/1991, FJ 5, y 64/1991, FJ 4).

Tampoco puede olvidarse que, salvo con ocasión del Tratado de Maastricht y en el concreto extremo de la plena participación de los ciudadanos de 
la Unión en procesos electorales municipales, nunca se consultó a este Tribunal sobre el encaje entre derecho europeo y derecho español en el campo reservado a la Constitución española.

Por lo tanto, nuestra Declaración de 1 de julio de 1992 es la única referencia jurisprudencial y precisamente lo que hizo fue reconocer la necesidad de reforma constitucional, rechazando cualquier interpretación que pretendiera sustraerse al texto del precepto constitucional que establecía únicamente el derecho al sufragio activo en las elecciones municipales para los que no fueran españoles, (art. 13.2 CE), frente al texto del art. 8.B, apartado 1 del Tratado constitutivo de CEE conforme a la nueva redacción dada por el art. G del Tratado de la Unión Europea, que extendía aquel derecho a todo ciudadano de la Unión que resida en un estado miembro que no sea nacional , tanto para ser electores como para ser elegibles en las referidas elecciones locales. Es decir, en aquella Declaración quedó perfectamente claro que las contradicciones textuales entre la Constitución y Normas europeas contenidas en un Tratado no podían resolverse por vía interpretativa, sino con la reforma constitucional.

No habiendo tenido ocasión este Tribunal de hacer ningún otro pronunciamiento, dado el carácter rogado de nuestra intervención, a instancia del Gobierno o de cualquiera de las Cámaras Legislativas, las situaciones de hecho y las que jurídicamente han sido aceptadas por los poderes públicos españoles respecto al encaje del derecho comunitario europeo, no pueden servir para impedir ahora un pronunciamiento claro, habida cuenta, además, que el Tratado que pretende establecer una Constitución para Europa es, en gran parte, una refundición de los anteriores, pero dando un salto cualitativo importante.

En efecto, el nuevo Tratado sí altera la situación anterior, no solo en la forma -llamar Constitución y articularla como tal ya es importante- sino también en el fondo, porque constituye a la Unión Europea con una personalidad jurídica única, como sujeto político, con clara vocación confederal, sino es que ya en si misma supone dicha confederación; porque, además, se establece una "Carta de Derechos Fundamentales de la Unión Europea", antes inexistente, lo que provoca que converjan derechos fundamentales reconocidos en la Constitución Española, en el Convenio europeo y en la Carta de la Unión; porque las competencias exclusivas de la Unión y las que se declaran compartidas (a las que no se da carácter exclusivo ni exhaustivo) tienden a la expansión, como ha venido sucediendo, sin perjuicio de algunos movimientos en sentido contrario motivados por razones económicas; porque las cautelas 
de la llamada "alerta temprana", la intervención de los Parlamentos nacionales y del Tribunal de la Unión Europea en materia de aplicación del principio de subsidiariedad, revelan la posibilidad cierta de conflictos competenciales futuros, que han llevado al Consejo Constitucional Francés a declarar que una ausencia de control nacional de decisiones obliga a reformar su Constitución.

Por estas razones no comparto el criterio de que el nuevo Tratado deja las cosas como estaban, pero es que, aunque así fuera, el texto del art. I-6 de la proyectada Constitución proporciona estado normativo a la jurisprudencia del Tribunal de Justicia de la Unión que ha venido estableciendo la supremacía del derecho europeo sobre cualquier norma de derecho interno, incluidas las constituciones nacionales. A título de ejemplo baste la Sentencia del Pleno de aquel Tribunal de 2 de julio de 1996 en la que, frente a la invocación por el Gran Ducado de Luxemburgo del párrafo segundo del art. 11 de su Constitución, declaró "A este respecto, basta con recordar que, según reiterada jurisprudencia, invocar las disposiciones del ordenamiento jurídico interno a fin de limitar el alcance de las disposiciones del Derecho comunitario implicaría lesionar la unidad y eficacia de dicho Derecho, por lo que no es posible admitirlo ( véase, en particular, la Sentencia de 17 de diciembre de 1970, Internationale Handelsgesellschaft, 11/70, Rec. Pg. 1125, apartado 3, y, por lo que respecta en particular al apartado 4 del articulo 48 del tratado, la Sentencia de 17 de diciembre de 1980, Comisión/Bélgica, antes citada, apartado 19)”.

Sirva esta cita literal para ilustrar lo que puede suceder si, ante contradicciones de nuestra Constitución con el derecho europeo, no se adoptan -aprovechando una ocasión verdaderamente histórica- reformas que, facilitando la aplicación de éste en forma ordenada, e incluso profundizando nuestra plena integración en Europa, establezcan también limites expresos para salvaguardar sus principios y estructuras básicas, fortaleciendo la seguridad jurídica y manteniendo, en lo esencial, la soberanía, incluso dentro de los propios criterios que preconiza la Constitución europea, que efectivamente anuncia límites a esa jurisprudencia del Tribunal de Justicia de la Unión Europea, pero que deberían quedar explícitos en nuestro propio Derecho, como ha hecho la República de Portugal añadiendo, recientemente, una apartado 4 al artículo 8 de su Constitución, que viene a introducir (esto es a constitucionalizar internamente) el texto del art. I-6 de la proyectada Constitución europea pero "en los términos definidos por el Derecho de la Unión, con respeto a los principios fundamentales del estado de derecho democrático".

3.- El problema que ahora se nos plantea no queda obviado, a mi juicio, con la brillante construcción doctrinal en que se asienta el criterio mayorita- 
rio, del que discrepo y que parece partir del axioma de que, habiendo de enfrentarse ordenamientos -el español interno y el europeo- y no normas concretas y siendo aquellos -los ordenamientos- de distintas áreas competenciales, no hay posibilidad real de contradicción y si la hubiera la propia Constitución, que se pretende establecer con el Tratado, tiene mecanismos y previsiones para resolverlo, incluso antes de que se produzca; es más, parece señalarse la imposibilidad jurídica de contradicción atendiendo a la comunidad de valores y a los respetos que el propio Tratado expresa sobre los principios inspiradores del derecho de los Estados miembros y sus estructuras básicas ( arts. 1-5.1 y I.2). Es esta una actitud un tanto ingenua y poco realista, dicho sea reiterando mi respeto por quienes puedan sostenerla. A mi modesto entender sería necesario que esto quedara claro sin posibilidad de desviación alguna.

4.- La construcción doctrinal a que me refiero pivota sobre la distinción entre primacía y supremacía de las normas jurídicas por un lado y por otro, sobre la interpretación del art. $93 \mathrm{CE}$, reconociéndole contenido material o sustantivo, además del orgánico-procedimental que le atribuyó la Declaración de este Tribunal de 1 de julio de 1992.

Tratando de entender, resumidamente, la argumentación empleada, cabe decir que la supremacía de la Constitución Española (entendida como el carácter superior jerárquico de una norma y fuente de validez de las inferiores) se mantiene, a pesar de que es el Derecho europeo el que ostenta la primacía (entendida como capacidad de desplazamiento de otras normas por su aplicación preferente) porque es la propia Constitución Española la que otorga esa aplicación preferente del ordenamiento europeo a través del art. 93 CE, que prevé la cesión de competencias derivadas de la Constitución.

Pues bien, aún admitiendo tan sutiles distinciones teóricas entre primacía y supremacía -que personalmente considero alejadas de la práctica en la aplicación del Derecho, en que vienen a confundirse- lo que no es asumible, reiterando una vez mas el respeto a la opinión contraria, es conferir al expresado art. $93 \mathrm{CE}$ un contenido de tal profundidad que por él pueda entrar y ser prevalente en su aplicación, cualquier norma de Derecho europeo derivado de un tratado internacional, aunque sea literalmente contradictoria con preceptos de la propia Constitución Española, sin mas que su articulación por Ley Orgánica, obviando así la reforma constitucional en cualquier caso, tanto en el pasado (la operada en el art. 13.2.CE como consecuencia de nuestra declaración 1/1992 habría sido, en realidad, innecesaria) como en el futuro. 
Tan radical apartamiento de dicha Declaración 1/1992 -que no comparto en principio- tenía que haberse expresado de la misma forma, es decir, de manera expresa y en la medida en que dicha nueva doctrina la corrige; pero es que, además, el art. $93 \mathrm{CE}$ tiene un contenido esencialmente orgánico procedimental, como se dijo de manera contundente -recordémoslo una vez más- en la Declaración 1/1992.

En efecto, el art. $93 \mathrm{CE}$ regula dos cuestiones temporalmente diferenciadas: en una primera parte su texto prevé cómo se puede autorizar (es decir, antes de prestar el consentimiento) "la celebración de tratados por los que se atribuya a una organización o institución internacional el ejercicio de competencias derivadas de la Constitución”, imponiendo que sea por Ley Orgánica y no solo por la previa autorización de las Cortes Generales, como en los demás tratados del art. $94 \mathrm{CE}$; tiene, pues, un contenido netamente procedimental. En una segunda parte y para después de haberse prestado el consentimiento al tratado de cesión del ejercicio de competencias derivadas de la Constitución, establece a qué órganos corresponde " la garantía del cumplimiento de estos tratados y de las resoluciones emanadas de los organismo internacionales o supranacionales titulares de la cesión", atribuyendo esa competencia de control, según los casos, a las Cortes Generales o al Gobierno; por lo tanto, tiene un contenido esencialmente orgánico.

La mención, que efectivamente contiene el art. $93 \mathrm{CE}$, a la posibilidad de cesión del ejercicio de competencias derivadas de la Constitución, sin establecer cuales pueden ser, ni en que forma pueden ser ejercidas, no permite otorgar al precepto un amplio contenido material y menos con la extensión y profundidad que refleja la Declaración de la que me aparto.

5.- En consecuencia, entiendo que la primera de las declaraciones que se contienen en la parte dispositiva debería reconocer que existe contradicción entre la Constitución Española y el art. I-6 del Tratado por el que se establece una Constitución para Europa, firmado en Roma el 29 de octubre de 2004.

También de forma consecuente habría que decir que no es suficiente el art. 93 de la Constitución Española para la prestación del consentimiento del Estado al Tratado referido.

Por lo que se refiere a la pregunta que afecta a los arts. II-111 y II-112 del Tratado, estoy conforme con la ausencia de contradicción respecto a la Constitución Española. 
Finalmente, no puedo pronunciarme sobre la pregunta referente al cauce del reforma constitucional que hubiera de seguirse, porque dado el contenido del debate en la deliberación, que no alcanzó a este extremo, no hice manifestación sobre el mismo y cualquiera que sea el criterio que ahora tenga, no me es posible expresarlo en este Voto particular, dadas las limitaciones establecidas en el art. 90 de nuestra Ley Orgánica.

En Madrid, a trece de diciembre de dos mil cuatro. 